\title{
Tumours of the thymus
}

\section{A review of 88 operation cases}

\author{
T. HOLMES SELLORS, A. C. THACKRAY, ANDA. D. THOMSON \\ From the Bland-Sutton Institute of Pathology, Middlesex Hospital, London, W.1
}

\begin{abstract}
Eighty-eight cases of thymoma are discussed with the object of trying to co-ordinate the histological and clinical features. The pathological specimens were in all cases obtained at operation. The pathology classification introduced by Thomson and Thackray in 1957 has been found to correspond adequately with the clinical pattern. The most common groups of tumours are basically epithelial and can be separated into five or six subdivisions, each of which has a separate pattern of behaviour. Lymphoid and teratomatous tumours also occur, but there were only two examples in this series. Clinically, separation of patients who suffered from myasthenia (38) and those who did not (50) affords the first main grouping. The majority of patients who had myasthenia gravis had tumours classified as epidermoid (19) and lymphoepithelial (14), the former with a more malignant appearance and behaviour than the latter. Removal of the tumour with or without radiation gave considerable and sometimes complete relief from myasthenic symptoms. Non-myasthenic thymoma (50) was usually discovered as a result of pressure signs or in the course of routine radiography. Spindle or oval celled tumours followed a benign pattern whereas undifferentiated thymoma was in every sense malignant, as also were teratomatous growths. Granulomatous or Hodgkin-like thymomas were of special interest and had an unpredictable course, some patients surviving many years after what was regarded as inadequate treatment. The place of radiotherapy as a pre- or post-operative agent complementary to surgery is discussed.
\end{abstract}

The thymus is an organ whose function and pathology were so veiled in obscurity that Keynes (1946), writing over 20 years ago, stated that 'if it is a member of the endocrine orchestra, its notes are so muffled that no one, even of the most able investigators, has been able to distinguish them'. As a result of much fascinating research work in recent years it is now accepted that in early life the thymus has a vital function to perform in the production of immunologically competent cells.

The thymus is also considered to play a part in the control of the function of the myoneural junctions and end-plates by means of an internal secretion. This supposition is based on the wellrecognized association of thymic abnormalities with myasthenia gravis, and though direct proof of a secretion has not been fully established, the indirect evidence is strong. In recent years, as the result of an association of myasthenia gravis with other auto-immune conditions and the presence of lymphoid hyperplasia with follicle formation, the theory that myasthenia gravis has an autoimmune basis has been advanced.

The process of involution of the thymus may be both extensive and rapid, but actual pathologi- cal changes in the thymus are rare. Neoplastic disorders of the gland have been recognized for over 60 years, but they are supposedly uncommon, and only a few attempts have been made to classify their appearance and behaviour. Such attempts in the past were made difficult by differences of opinion about the nature of the cells of the normal thymus.

One of the disturbing factors when dealing with tumours of the thymus in general has been the difficulty of making any prediction as to their future course or behaviour. A small encapsulated thymoma, easily and cleanly removed, might be followed by an early recurrence, whereas patients with gross infiltrating tumours sometimes survived. Similarly, the histological findings in these tumours could not be used as a sound basis for prognosis; there were too many contradictions.

The early accounts of thymoma did not throw much light on the nature of these tumours. The descriptions were sometimes conflicting, and cases which would now be classified as thymoma were reported as lymphosarcoma, lymphoma, and so on. With the rocognition that the reticular cells of the thymus are epithelial and that the small 
round cells are no more than lymphocytes, it has become possible to classify the tumours on a sounder basis. In 1957 Thomson and Thackray put forward a classification based on a study of all surgical and necropsy specimens of anterior mediastinal tumours seen at the Bland-Sutton Institute of the Middlesex Hospital over a period of 20 years. As this classification will be used here it seems desirable to recapitulate its mean features.

The normal thymus is composed of lobules, each of which is made up of epithelial cells (epithelial reticular cells) and lymphocytes. The proportions of these vary; in the cortex the lymphocytes form a densely packed zone with sparse epithelial cells, whereas in the medulla epithelial cells are more prominent and include Hassall's corpuscles, structures derived from the epithelium and unique to the thymus. As a first step, thymic tumours are divided into epithelial, lymphoid, and teratomatous groups (Fig. 1). The two latter groups are very small in relation to the epithelial group, in which several

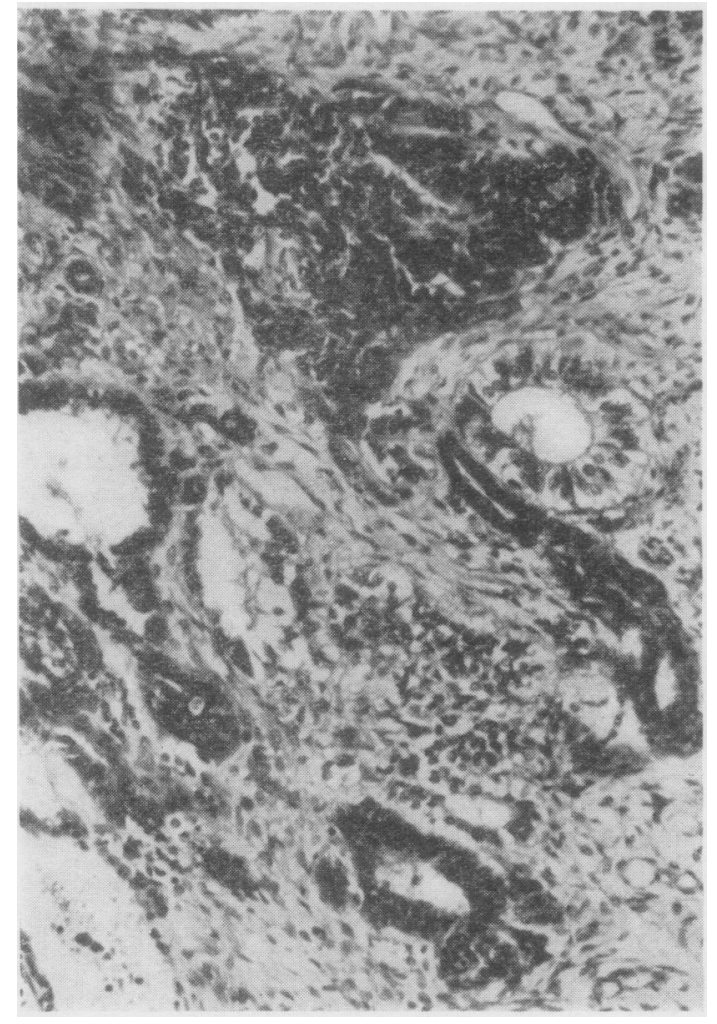

FIG. 1. A malignant thymic teratoma showing both connective tissue and epithelial elements. One welldifferentiated tubule is present in the field. $\times 145$.

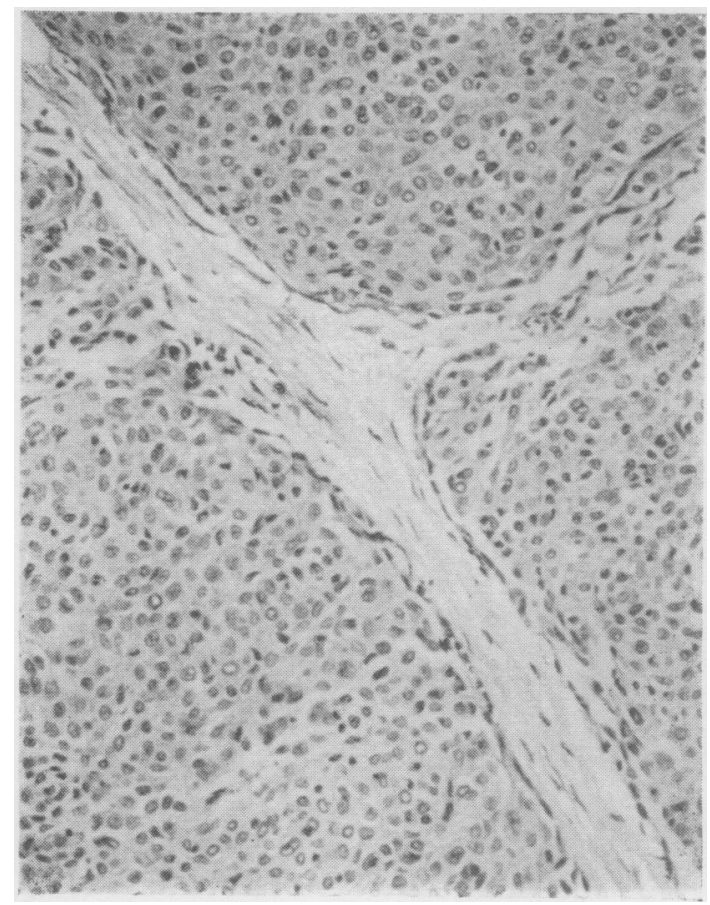

FIG. 2. An epithelial thymic tuniour of epidermoid or squamoid type. The degree of lymphocytic infiltration varied considerably: in the field shown there were scarcely any. A radiograph of this case is shown in Fig. $14 . \times 160$.

subdivisions can be recognized. It should be noted that thymic tumours classed as 'lymphoid' contain no epithelial elements, whereas most 'epithelial thymomas' have an admixture of lymphocytes. The tumours of the epithelial group are subdivided according to the shape and arrangement of the epithelial cells, no account being taken of the degree of lymphocytic infiltration, which varies greatly from tumour to tumour and in different areas of the same tumour. In the commonest type the epithelial cells have a definite epidermoid or squamoid appearance (Fig. 2), sometimes with easily recognizable attempts at the formation of Hassall's corpuscles (Fig. 3). In the next commonest type the epithelial cells are large, pale, and uniform in size; as in this type there is always a heavy lymphocytic infiltration, it is referred to as the lympho-epithelial type (Fig. 4). In other tumours the epithelial cells may be approximately oval in shape, with a tendency to a whorled arrangement (Fig. 5); or they may have a greatly elongated spindle form, only recognizable as a type of epithelial cell by com- 


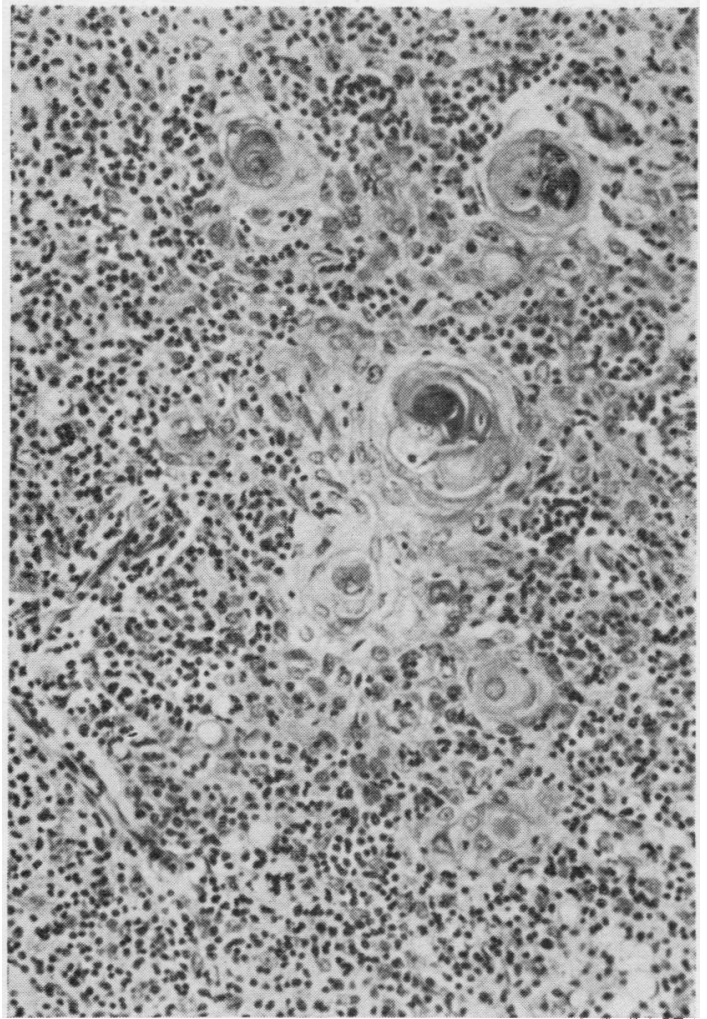

FIG. 3. An epidermoid thymic tumour with formation of structures resembling Hassall's corpuscles. Tumour from a man aged 40 (illustrative case E. S.). $\times 185$.

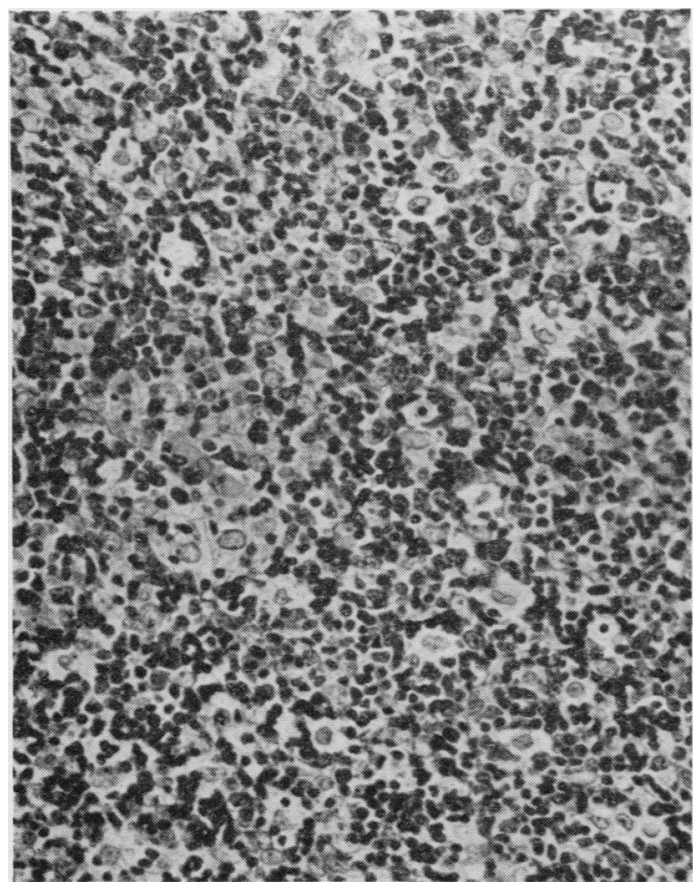

FIG. 4. The lympho-epithelial type of thymic tumour, in which the epithelial cells are large and pale and there is a uniform, often heavy, lymphocytic infiltrate. $\times 190$.

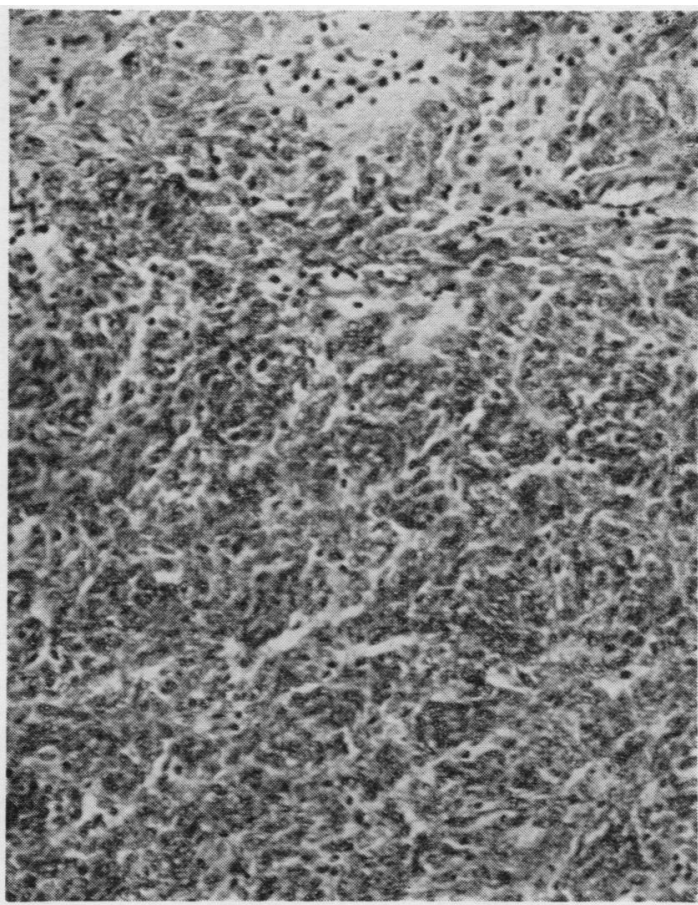

FIG. 5. Oval-cell thymoma: specimen shown in Fig. 19 (illustrative case $L . H$.). The epithelial cells are small and uniform in size and show a variable tendency to a whorled arrangement. $\times 160$.

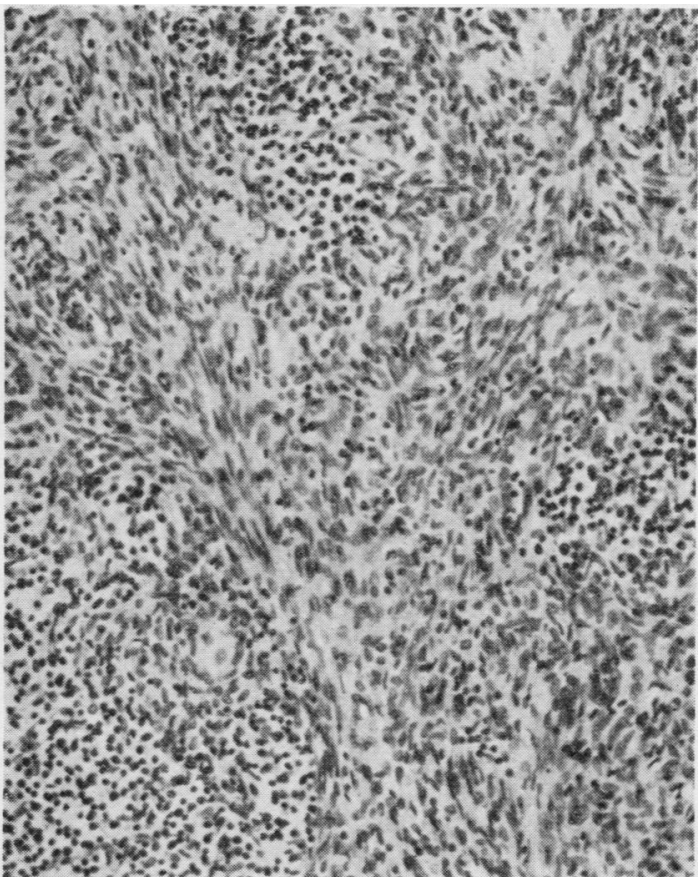

FIG. 6. Spindle-cell thymoma. Streams of elongated epithelial cells are present: where the cells are cut transversely they are with difficulty distinguished from the accompanying lymphocytes. $\times 190$. 
parison with normally involuting thymuses (Fig. 6). The remaining subdivisions are the granulomatous thymoma (Fig. 7), the undifferentiated epithelial type, and a category in which are placed tumours so affected by irradiation before examination that the cell type can no longer be clearly identified (Fig. 8).

The first observation to relate a thymic tumour with myasthenia gravis was made in 1901 by Weigert, who recognized this association as the result of a necropsy examination. Since that time thymectomy has developed into a recognized form of treatment for selected cases of myasthenia gravis, and during the course of operation a number of tumours have been found within the gland. These may have been suspected before operation but were often unexpected findings.

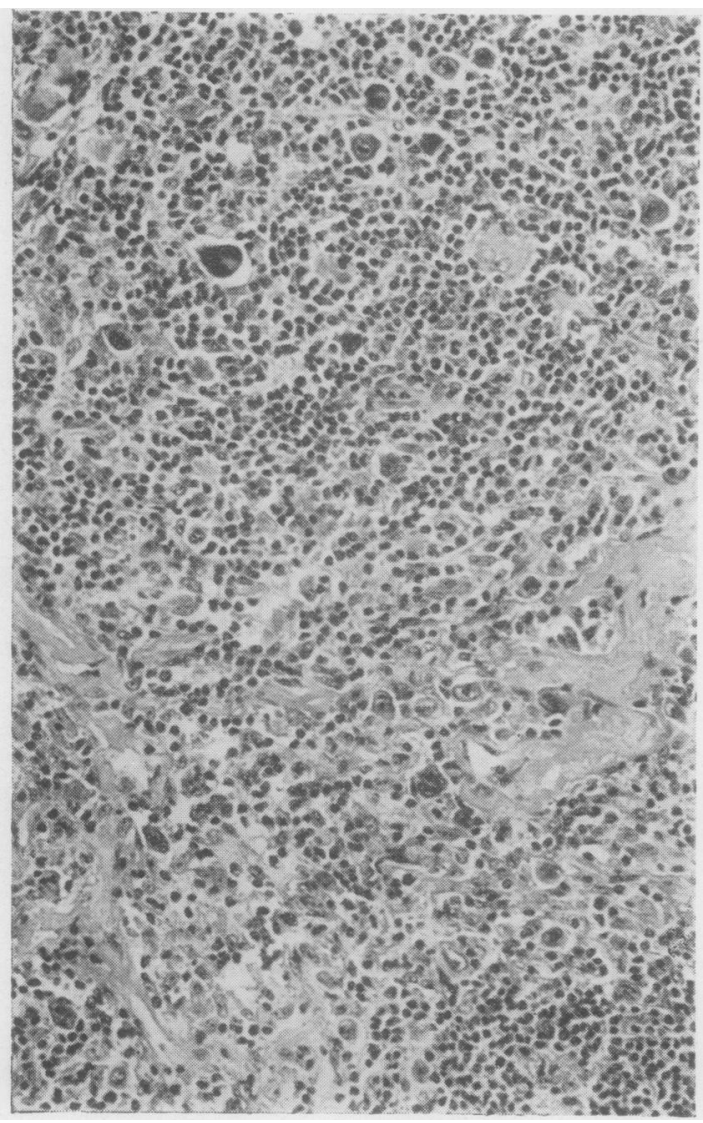

FIG. 7. Granulomatous thymic tumour (see Fig. 20). The epithelial cells are isolated or in small groups among the proliferating granulomatous tissue in which fibrosis is occurring. Some multinucleate epithelial cells are present. $\times 190$.

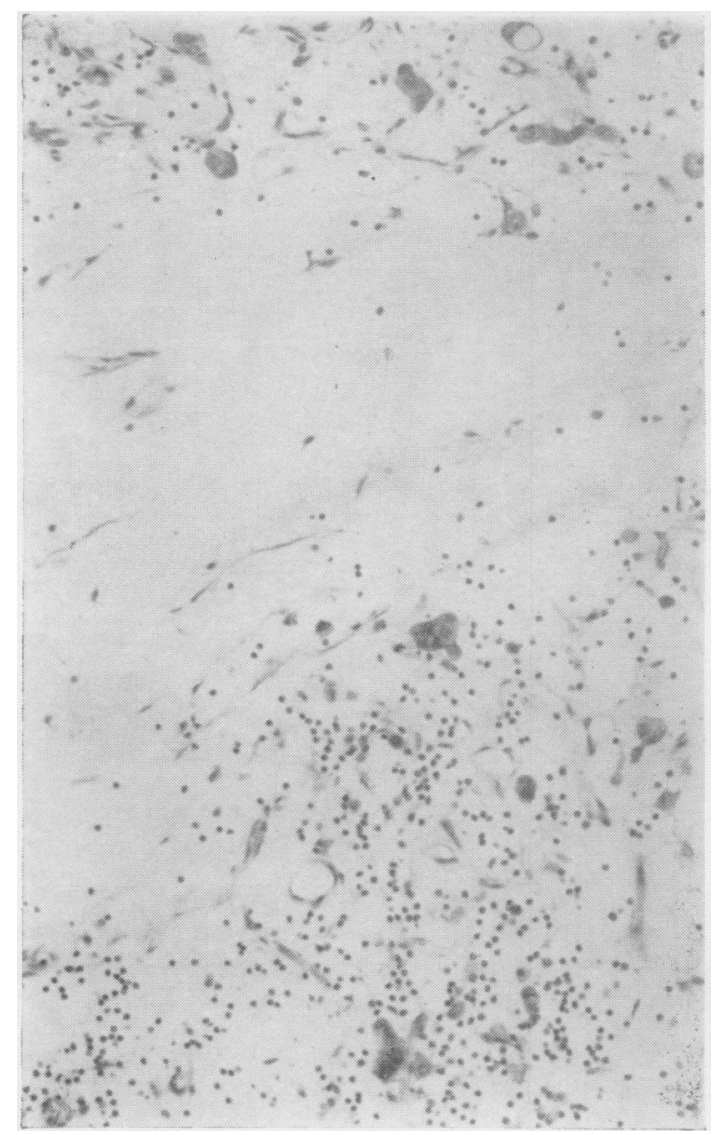

FIG. 8. Small groups of tumour cells surviving in a thymic tumour irradiated before removal: it is not possible to classify such growths. See Fig. 12 for radiographs of this case. $\times 160$.

Apart from tumours associated with myasthenia gravis there is another group of thymic growths. These present as mediastinal masses, and their thymic origin and neoplastic nature are only revealed as the result of microscopic examination. These thymomas come to notice if they cause pressure on anterior mediastinal structures. Alt arnatively, they may be discovered accidentally during the course of routine radiological examination.

A preliminary distinction can therefore be made between those thymomas that are associated with myasthenia gravis and those that are not, and this is the first division that has been made on clinical grounds in the present series of cases. Each division has then been broken up into the histological grouping outlined above. 
Sellors (1961) reported 50 operative cases and was able in general to relate the clinical features to the classification of Thomson and Thackray (1957). This present paper is a continuation of these two papers. It is mainly concerned with the diagnosis, surgical treatment, and prognosis of tumours of the thymus, but includes some references to their histological classification and relationship to myasthenia gravis and to the effect of their removal on the latter condition. It is based on 88 cases in which a large part or the whole of the tumour was removed at operation. The histological preparations were studied by more than one observer before an attempt was made to correlate the agreed classification with the clinical features of the case. The follow-up period has varied between six months and 15 years.

It is impracticable to draw inferences or deductions as to the incidence of these tumours in the population as a whole. Part of the material has been derived from the normal practice of thoracic surgery, but an unduly high proportion of the myasthenic thymomas were gathered in the course of thymectomies for myasthenia gravis performed at the National Hospital for Nervous Diseases, Queen Square, London.

\section{THE THYMUS AND MYASTHENIA GRAVIS}

The generally accepted theory regarding the aetiology of myasthenia gravis is that the function of the myoneural junction has been affected by an abnormal internal secretion from the thymus. The actual motor end-plates, when examined by intra-vital staining, show certain changes which appear to be irreversible in the advanced condition. The improvement obtained by injection of edrophonium or neostigmine is an important factor in diagnosis in the early stages, and thymectomy is performed on the assumption that by removal of the gland a cholinesterase factor which adversely affects the myoneural junction tissue will be reduced. There is no evidence to indicate which type of thymic cell is responsible for an internal secretion, though the epithelial rather than the lymphocytic element is more probable.

The effects of removing the thymus gland in myasthenia gravis are uncertain. Some patients derive such benefit that they can give up drugs altogether, though most patients continue with a 'token' dose which may have to be increased slightly from time to time as the process fluctuates. Other patients improve but not to such a marked extent and need to continue anticholinesterase drugs even though the quantity is reduced. The increasing safety of handling severely ill myasthenic patients, particularly with the help of tracheostomy and intermittent positive pressure respiration (I.P.P.R.), has widened the scope of surgery considerably, especially if a tumour is suspected.

Myasthenia gravis which is associated with a tumour often has a sudden and sharp onset. Ocular signs and symptoms are present in nearly all cases, but the rapid development of bulbar or skeletal weakness is an indication for surgery if neostigmine does not give adequate control. Difficulty in. eating or swallowing are definite indications for considering thymectomy, particularly if control by drugs is not straightforward. It is in this type of patient, particularly in middle age, that a thymoma should be suspected. It is not always realized that increasing doses of this drug can lead to a state of poisoning with symptoms not dissimilar from those of severe myasthenic weakness. In such a position tracheostomy and I.P.P.R. are invaluable and permit drugs to be withdrawn over the period of active surgery. They can be started again as required when respiratory control is no longer necessary.

When thymectomy is undertaken for myasthenia gravis and the condition of the gland is that of simple hyperplasia, the sex and age grouping favours young adult women, whereas with tumours the average age is higher and the proportion of men to women is greater (16 men, 22 women).

Rowland, Hoefer, and Aranow (1960) recorded three patients in whom myasthenic symptoms developed after thymectomy, and they quote seven other examples. There is not sufficient evidence to determine whether all thymic tissue had been excised at operation, and it is also difficult to be certain that the condition was not already developing at the time of surgery. One of our patients who came under this heading had a story of remaining unconscious for a long period after administration of a muscle-relaxant anaesthetic, but the condition was not diagnosed as being myasthenic until after the operation. We have previously recorded the importance of full anterior mediastinal clearance to ensure that residual islets of thymic tissue enclosed in mediastinal fat are not left behind.

Another significant factor in considering the advisability of thymectomy in myasthenia gravis is that small tumours cannot be visualized radiologically and the presence of a thymoma is 
often an unexpected finding. Careful radiology may identify some of the larger tumours, but the definition in general is poor.

The incidence of thymoma in patients with myasthenia gravis is usually given as about $15 \%$ (Keynes, 1954 ; Castleman, 1960), but in the Myasthenia Gravis Clinic at Massachusetts General Hospital 56 tumours were noted in 658 patients under observation, giving an incidence of $8.5 \%$ (Perlo, Schwab, and Castleman, 1965). Our own experience, which concerns solely thymectomy cases, shows that a thymoma was present on 38 occasions out of a total of 139 operations performed $(27 \%)$.

Pathologically two types of epithelial tumour dominate the picture from the viewpoint of frequency - lympho-epithelial and epidermoid. Thirty-three out of $\mathbf{3 8}$ thymomas associated with myasthenia gravis were in these two categories. Of the remaining five tumours, three were oval or spindle celled.

The lympho-epithelial thymoma is macroscopically benign in appearance. It is usually small, 2 to $5 \mathrm{~cm}$. across, rounded, and encapsulated within thymic tissue. The results following its removal are generally satisfactory.

The epidermoid thymoma is more malignant in appearance. It is usually a large, whitish, infiltrating tumour which invades the great veins and involves adjacent glands. The results are not as satisfactory as those with lympho-epithelial tumours, but, considering the apparent inadequacy of surgical clearance on a number of occasions, the figures are better than might be expected.

\section{NON-MYASTHENIC THYMOMA}

In this series 50 out of the 88 tumours studied were not associated with myasthenia gravis and presented simply as mediastinal tumours. Of these, a proportion showed signs or symptoms. Lattes (1962) gave a figure of 32 patients with pressure signs out of 77 with non-myasthenic thymoma, and our experience corresponds with this. The majority of patients came to notice as the result of routine or incidental radiological examination of the chest.

The nature of these radiological opacities cannot be determined with any accuracy without histological examination. A smooth, rounded outline may suggest a benign tumour or cyst, but no more. A more irregularly outlined mass in the anterior mediastinum will present considerable difficulties in the differential diagnosis. A thymic origin may be suspected, but proof is unlikely until the results of microscopical examination are available.

Some benign tumours are relatively slow to을 enlarge, whereas others expand freely into the lung fields and attain considerable dimensions?

Thymomas confined to the upper mediastinump are most likely to produce pressure effects, parti cularly on the easily compressed left innominateand common innominate veins. Pressure signs occur almost as readily with 'benign' tumours asw with 'malignant' ones owing to the limited space? in which they are confined.

\section{RADIOLOGY}

The normal thymus gland, even if enlarged, doesw not cast a radiological shadow, though in infants? a 'sail-like' or triangular shadow at the apex of thelung fields may be produced by an enlargeds thymus gland. This type of picture is often con fused with atelectasis of the upper lobes.

Many thymic tumours, particularly in the myasthenic category, are not recognized because of their small size and lack of density. Smallo thymomas require special studies if their outline is to be delineated. Extra-penetration films, specialo apical views, lateral tomographs, pneumomedias $\frac{0}{\mathrm{D}}$ tinum, and even angiocardiography may be required before an ill-defined or suspiciouso shadow can be identified as a possible tumour, but even then there is no distinctive feature that enables it to be called a thymoma. All that canbe said is that any anterior mediastinal tumour which is separate from the vascular pattern may be of thymic origin.

Larger tumours, usually non-myasthenic, are more simple to recognize. They extend laterally from the main mediastinal shadow into eithers lung field. There is little to distinguish them from a dermoid cyst or teratoma, glandular masses? retrosternal goitre, lipoma, fibroma, and othe pathological possibilities.

The outline of the 'benign' thymoma is usuallyos smooth or oval, extending without displacement of mediastinal structures into the lung field (Figs $9 \mathrm{a}$ and b). Irregular shadows with indefinite margins suggest infiltration which may be con firmed by a raised diaphragm (phrenic nerve paralysis) or aphonia (vagus or recurrent laryn geal nerve involvement). Here again the distinc:tion between a mediastinal and a pulmonary growth may only be decided after bronchoscopy and even thoracotomy. Direct invasion of the
lung occurs in some instances.

The response of a thymoma to radiation is often dramatic, and radiotherapy as a combined 


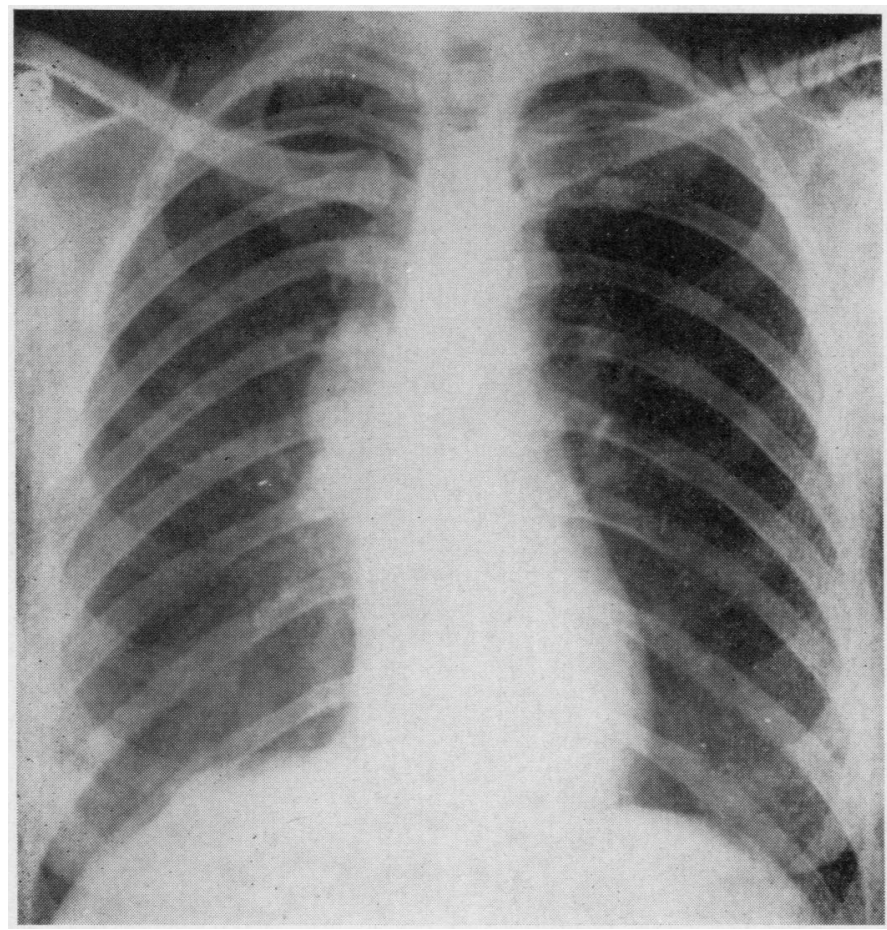

FIGS 9 a and b. Lympho-epithelioma (illustrative case $E$. $P$.). A right-sided mediastinal opacity. The lateral view shows the oval tumour faintly outlined in the anterior mediastinum at the level of the second to fourth costal cartilages.

FIG. $9 \mathrm{a}$

diagnostic and therapeutic method is of considerable value in cases of a mediastinal shadow whose origin is uncertain (Figs 10a and b). Many thymomas, teratomas, and glandular masses show rapid regression while cysts and retrosternal goitres remain unchanged. The place of radiotherapy in relation to treatment will be discussed later.

\section{PRESSURE SIGNS}

Infiltrating tumours are more likely to produce pressure signs than encapsulated ones, which as they enlarge tend to expand into the lung fields.

As has already been mentioned, this does not apply to growths restricted to the superior mediastinum, where space is restricted and small increases in tumour size can produce marked changes.

Pain is common as an early feature of pressure, but the most obvious sign is progressive obstruction of the left innominate vein or superior vena cava (common innominate vein) with venous engorgement and swelling of the face, neck, and arms (Fig. 11). Asymmetrical engorgement, more noticeable on the left, suggests obstruction of the left innominate vein only. Displacement and

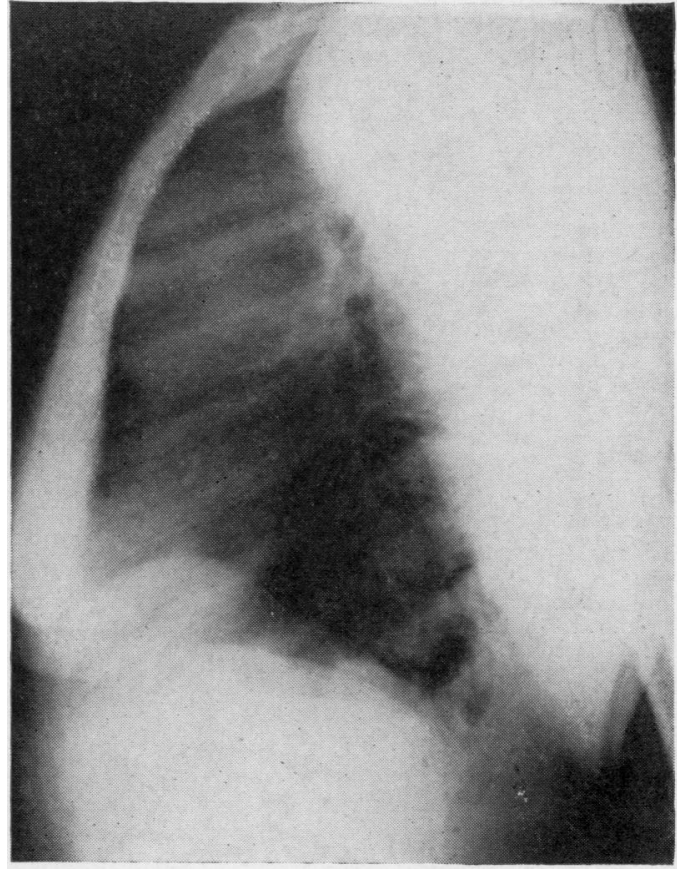

FIG. $9 b$ 


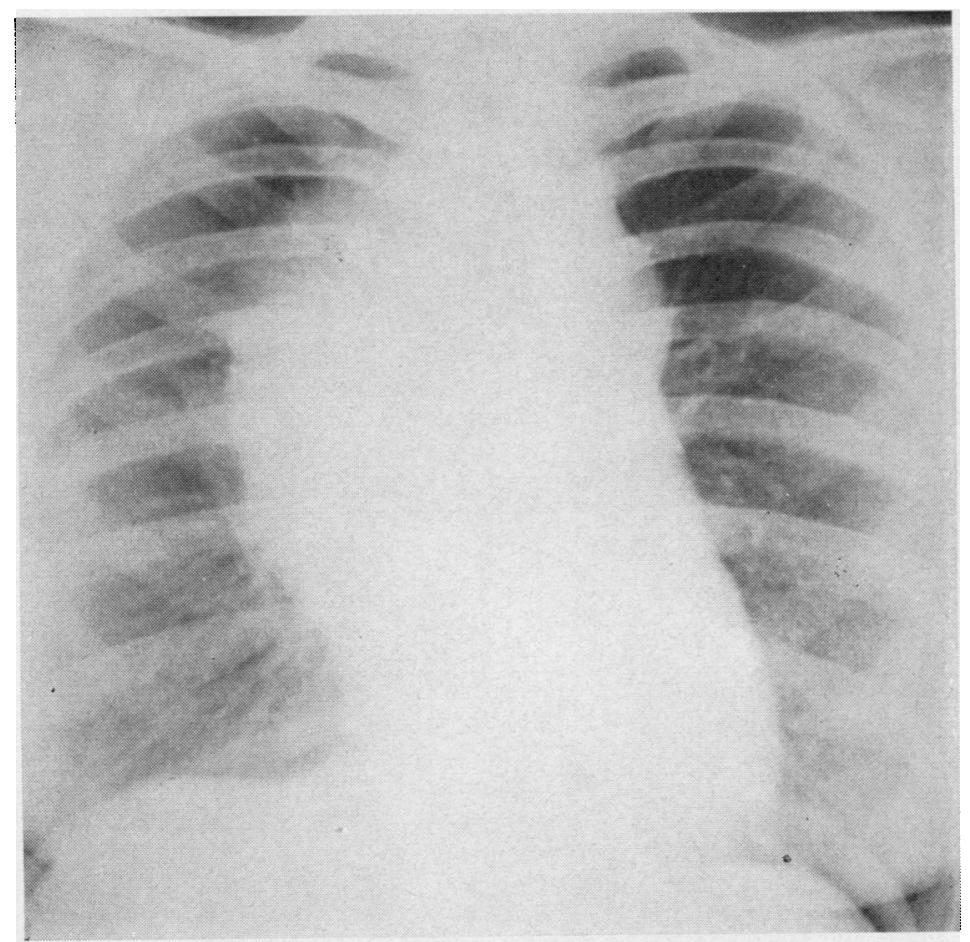

FIG. 10. Granulomatous thymoma. (a) Large mediastinal mass infiltrat $-\vec{\omega}$ ing the right lung field. An extensive but incomplete resection including the lung, part of the right atrium, and phrenic nerve was carried out? This was followed by a full course of radiotherapy. (b) Shows theco appearance a year later. The patient remained well for 12 years, when she developed carcinoma of thebreast and died soon after.

FIG. $10 \mathrm{a}$

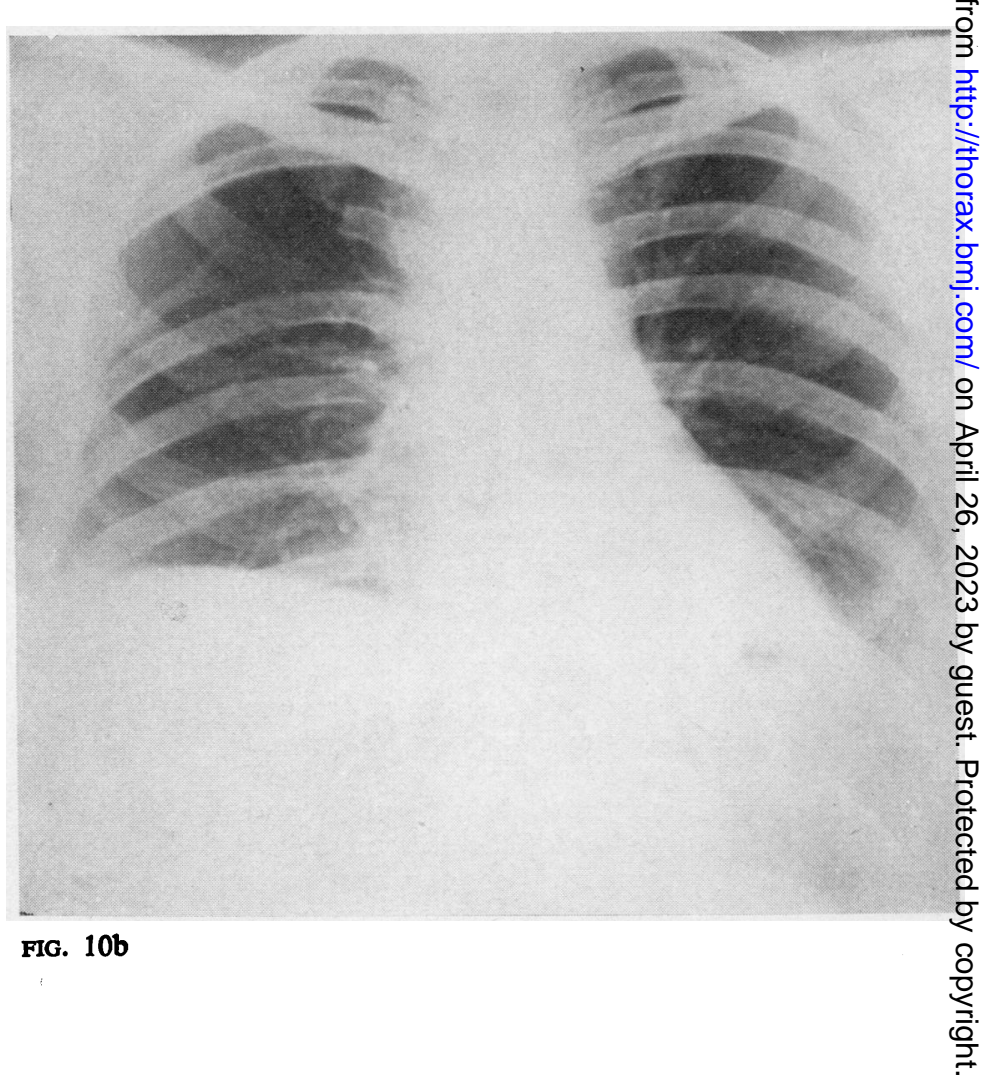




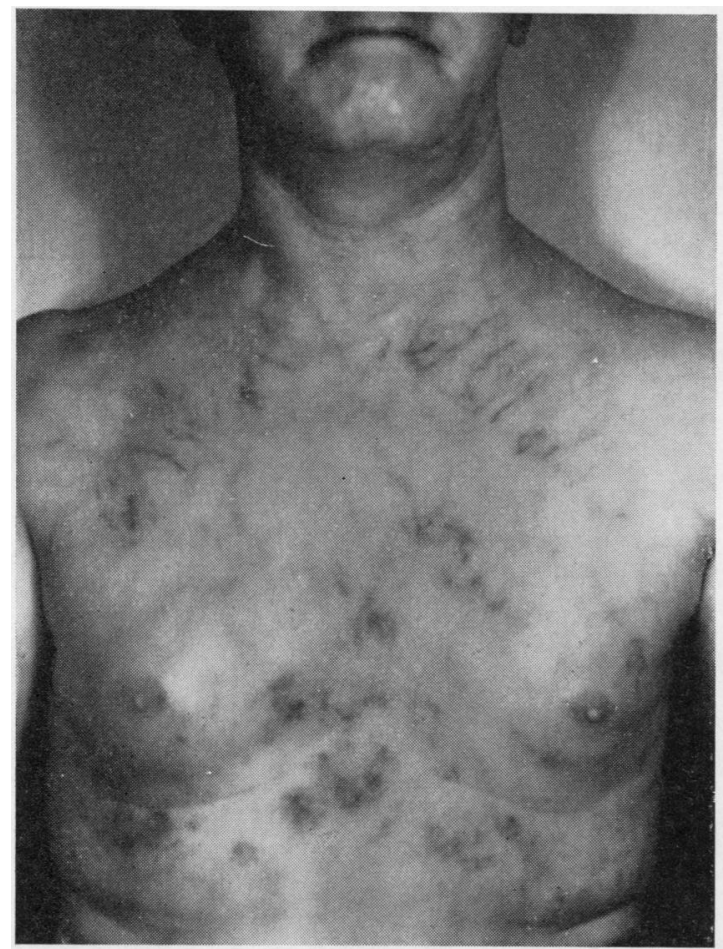

FIG. 11. Infra-red photograph to show collateral veins in a patient with superior vena caval obstruction caused by infiltration from an undifferentiated epithelioma.

deformity of the trachea may occur and in its early stages is associated with an irritating cough. The right phrenic nerve is likely to be involved if the superior vena cava is obstructed, and loss of voice may indicate interference with the left vagus or recurrent laryngeal nerves. Interference with swallowing is uncommon.

Once infiltration of the pericardium and pleural membranes occurs there is a predilection for invasion of the ascending aorta at the level of its upper pericardial reflection and a spread of the growth in a plaque-like mass over the lung roots involving the lungs and pleura. Though most patients with this form of carcinoma do not survive long, we have several instances of survival in good health for a number of years. Implantation secondaries on the pleural surfaces leading to an effusion have also been encountered, but distant metastases are uncommon.

\section{BENIGN OR MALIGNANT}

The words benign and malignant are reluctantly used in most papers dealing with thymic tumours, and when they do appear they are often cautiously placed between inverted commas. Indeed, the use of the very word thymoma is often a device to avoid the issue. For if it is agreed that the reticular cell of the thymus is epithelial in type, its tumours should be adenoma or carcinoma. The distinction would normally be made microscopically on the state of differentiation of the tumour cells and evidence of infiltrative growth. In thymic tumours both these criteria are difficult to assess, particularly the question of differentiation. For example, the spindle-cell epithelial tumourat one time quite understandably called a spindlecell sarcoma-would seem to be undifferentiated, but clinically these tumours are usually benign. The mediastinum is a site where even pathologically benign tumours are likely to prove fatal from pressure effects; and it must be remembered that incomplete removal of a benign tumour will be followed by recurrence and also possibly by dissemination if tumour cells have been spilt in the operative field. Subsequent developments must be cautiously interpreted in deciding whether a certain tumour is to be regarded as benign or malignant. Until large numbers of cases have been critically followed up it is probably best to give non-committal names to some of these tumour types and to assess their behaviour later.

Apart from the predominantly epithelial thymoma the true lymphoid tumour exists, though we have no definite example in this series. These lymphoid tumours are highly malignant and may be associated with leukaemia. It may be argued that the teratomatous thymoma has no place in our classification, but histologically the elements of thymic tumour are so involved in the teratomatous tissues that they cannot be separated. The behaviour of these latter growths is also that of a highly malignant tumour.

Metastasis as a feature of malignancy is found in only two or three groups of thymoma. It can take the form of multiple seedling deposits in the pleura or pericardium, with the production of effusion, and it can spread along the lymphatics of the thymus to the regional glands in the supraclavicular fossa or through the ligamentum teres to the abdominal aortic glands and thence to the groins. This form of dissemination is seen in the granulomatous or Hodgkin-like thymoma but also occurs in epidermoid tumours. Distant metastasis, contrary to what has been said elsewhere, occurs in the obviously malignant forms, which include the undifferentiated epithelioma and teratoma.

The microscopical appearance of any thymoma can only be used as a rough guide to the future 
Histology can only be based on cell types and forms observed, and in these tumours the findings at operation and the subsequent behaviour of the patient have to be taken into account. There have been cases in which infiltrating masses with seedling deposits and an adverse histological prognosis have been present and yet the patient has survived for years after an obviously inadequate removal. Per contra, an apparently benign encapsulated tumour, easily removed, has been followed quite shortly by death from recurrence.

\section{TREATMENT}

The two available methods of treatment for thymoma are excision and radiotherapy, alone or in combination. No patients treated by radiotherapy alone are included, as this series contains only those in whom the specimen was obtained at operation.

Earlier articles on this subject emphasized the necessity for using radiotherapy as a preliminary control, and suggested that surgery alone was unsatisfactory. This has not been our experience, and in consultation with our radiotherapist colleagues we have evolved a plan of campaign for each type of tumour, though admittedly circumstances have varied the overall plan.

SURGERY The surgical approach depends on the situation of the tumour. A postero-lateral or antero-lateral thoracotomy is suitable for masses that project into the lung fields and are unilateral, but the most convenient incision for the average centrally placed growth is a median sternotomy. Originally the division of the sternum was only carried to the level of the fourth intercostal space, but splitting of the sternum over its full length is now preferred. This allows complete exposure of the anterior mediastinum. Free incision of one or both pleurae is often required to ensure adequate access, and where tumour infiltration occurs the excision should be extended as far as is felt to be compatible with operative safety.

Pericardium can be freely sacrificed and ligation or excision of the left innominate vein is permissible. The common innominate vein or the superior vena cava has to be left patent unless (as in one case, Figs 12a, b, and c) a collateral circulation has already been established. Without collateral channels excision of the vena cava is incompatible with survival.

Fringes of lung are easily removed and the raw edges oversewn, and occasionally one phrenic nerve can be sacrificed if this is necessary to ensure good operative clearance. In two of ours patients a formal lobectomy was added to the tumour excision to effect clearance.

For saddle-shaped masses across the aorta $\frac{\bar{s}}{\sqrt{5}}$ bilateral anterior third or fourth space thoraco- $\triangle$ tomy with transverse section of the sternum has given good access to the lateral aspects of themediastinum, particularly at the lung roots.

When the tumour is situated within the thymusw gland itself, dissection from the level of the diaphragm should be extended to include fat in $\vec{x}$ the pleural fringes as well as the gland itself $f_{N}^{i}$ Lymph nodes at the origin of the internato mammary vessels and in the anterior intercostato spaces should also be removed.

Complete excision of the infiltrating masses may not be practicable because of invasion of vital structures, but after as full a clearance as్d possible has been achieved the exact position of any residual growth should be noted and markegh by metal clips to help the radiotherapist.

In patients who have already been subjected to a full course of radiation surgery can be under taken as soon as the treatment has been completed $\frac{\partial}{\circ}$ The field of operation is sometimes surprisinglis

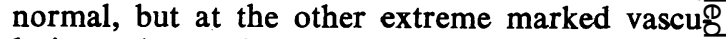
larity and a markedly adherent mass of ill-define tissue may be found.

RADIOTHERAPY Irradiation plays an important part in the treatment of thymic tumours. Many of these are extremely radio-sensitive and diminis rapidly after exposure (e.g., Fig. 10 ; Figs 13a, bo and $c)$. On the other hand, we have evidence that complete resolution is hardly, if ever, achieved. A high proportion of cases that have beep explored subsequent to adequate radiation have shown viable residual tumour cells. It is difficuls to determine the response to radiotherapy, but broadly speaking, the epidermoid, undifferentiated and granulomatous forms give a good initia result. Oval or spindle celled tumours an\& lympho-epitheliomas are not affected to the sams extent. Many patients have received radiatiod before the diagnosis has been made and have gained considerable benefit from this treatmento but it is imperative that this should be followe with the object of removing everything resembling tumour tissue. In patients presenting with an irregular mass or one which is rapidly growing the initial treatment should be radiation, and a good response is obtained treatment should bo continued to a full tumour dose of 4,000 to 6,000 ? As soon as this is complete, surgery is then undertaken with the object of trying to excise af 


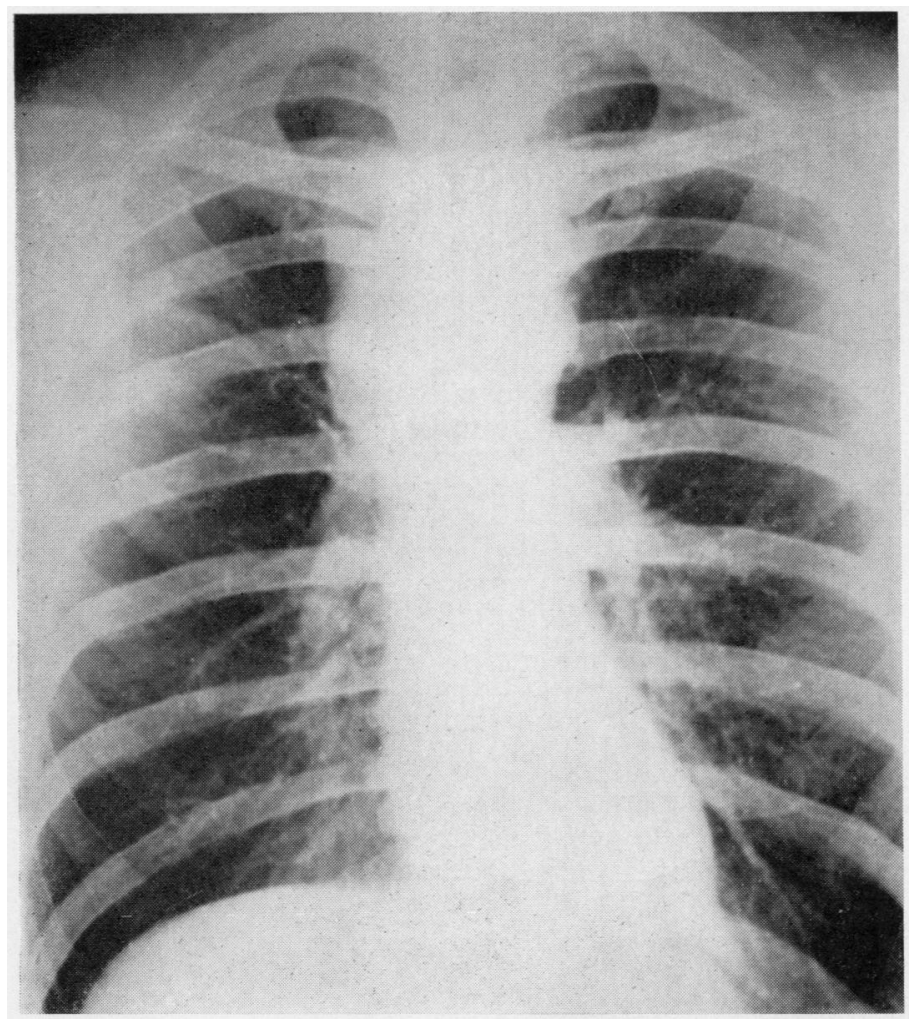

FIG. $12 \mathrm{a}$

For legend see p. 204

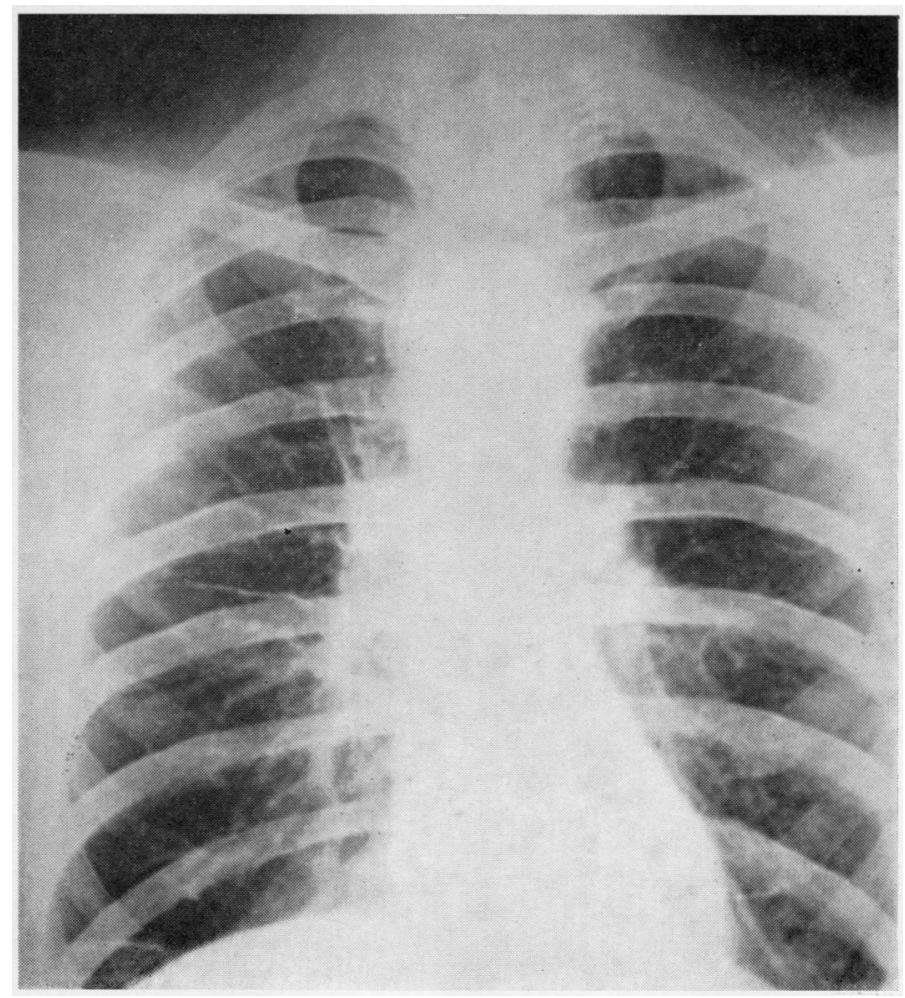

FIG. $12 \mathrm{~b}$ 


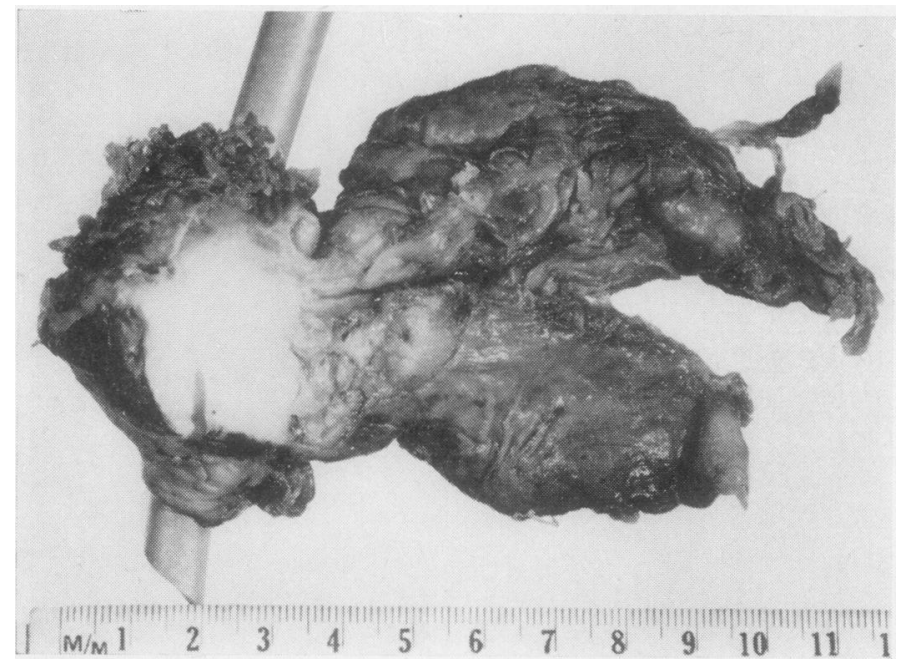

FIG. 12. Irradiated epithelial thymoma. $\stackrel{\overrightarrow{\vec{S}}}{\stackrel{\vec{P}}{2}}$ (a) Radiograph shows a shadow extend-음 ing from the right upper mediastinum. 드 Clinically there was complete obstruc- $\overline{\frac{D}{2}}$ tion of the superior vena cava. (b) $\vec{\nabla}$ Radiotherapy produced dramatic symp- $\mathrm{Q}$ tomatic relief and reduction in the size of the shadow. (c) The specimenobtained at operation shows surviving. groups of malignant cells in the tissue $\vec{\omega}$ surrounding the superior vena cava, $\odot$ through which a tube has been passed. $\overrightarrow{\vec{x}}$ Since a collateral venous circulation had already been established no prob- $\mathrm{N}$ lem resulted from resection of the vena $\mathrm{\omega}$ cava. The patient is alive and well $11 \vec{\omega}$
years later.

FIG. $12 \mathrm{c}$

abnormal tissue. There does not appear to be any advantage in postponing surgery in these patients.

In our experience there has been little difference in the result between those patients treated primarily with surgery and followed by radio therapy and those initially irradiated and then treated surgically. One advantage of primary sur- gery is that the radiotherapist can know the

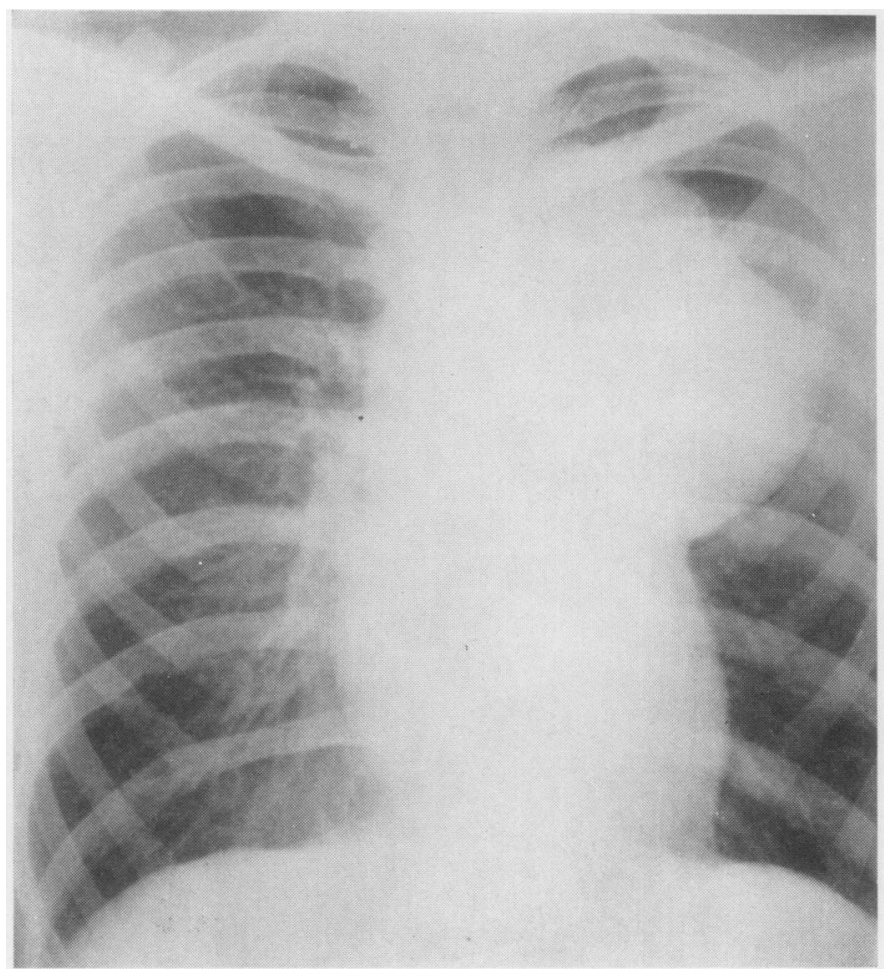

FIG. 13a. For legend see p. 205. 


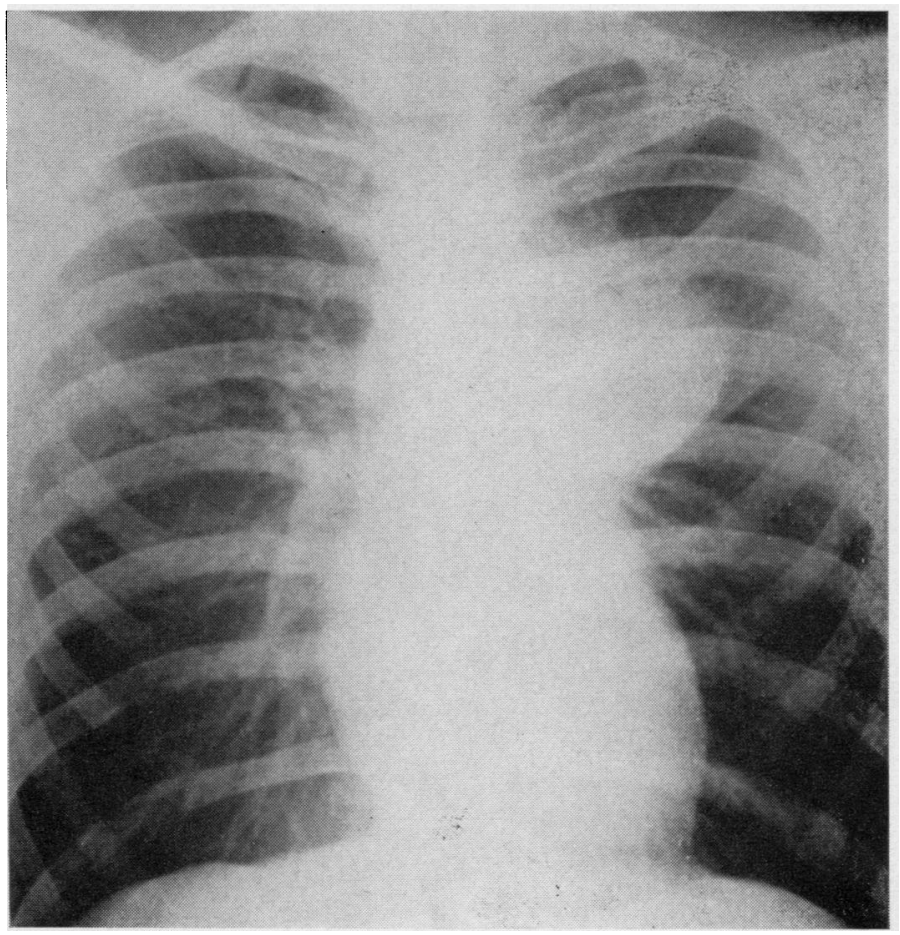

FIG. 13b

pathology of the tumour and can be given the precise localization. On the other hand, if irradiation comes first, the surgeon is faced with a less extensive mass but one that may be more vascular and technically more difficult than it would have otherwise been.

We do not advocate radiotherapy as the initial treatment in cases that appear to be radiologically 'benign', that is, with smooth outlines and little evidence of infiltration.

Following this introductory section on thymic tumours in general the categories given in the classification are to be described in more detail and illustrated by an account of what may be regarded as one or two typical examples in that group.

\section{DIFFERENTIATED EPITHELIAL (EPIDERMOID) THYMOMA}

(25 cases, 19 with myasthenia; 16 alive, 5 dead within three years, 4 later deaths)

This is one of the two forms of tumour frequently associated with myasthenia gravis and should be regarded as a tumour of definite, though lowgrade, malignancy (Fig. 14). It is an infiltrating and invasive tumour originating within the obvious substance of the thymus gland and is

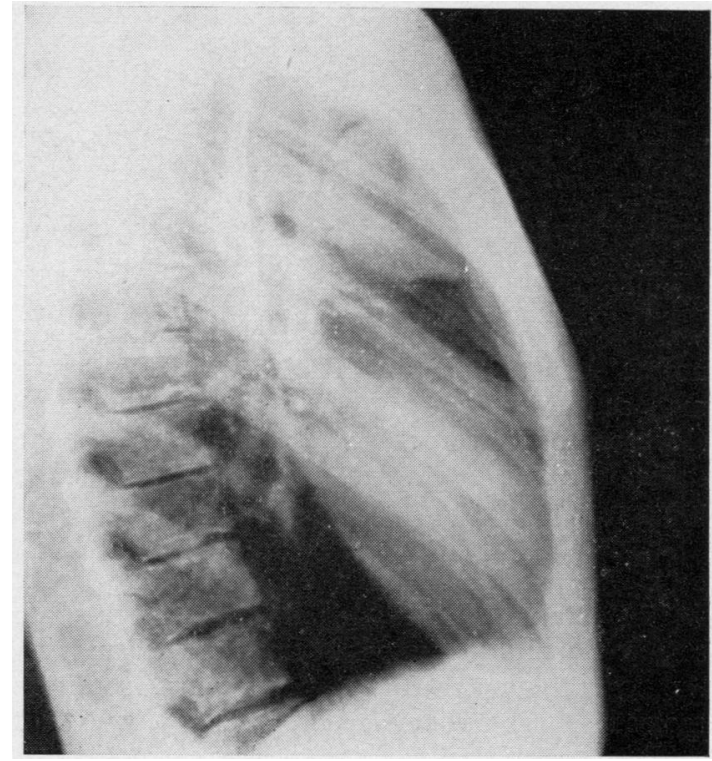

FIG. $13 \mathrm{c}$

FIG. 13. Irradiated thymoma. (a) Rounded tumour arising from the anterior mediastinum extending into the left lung field. (b and c) P.A. and lateral views after one month's radiotherapy. 


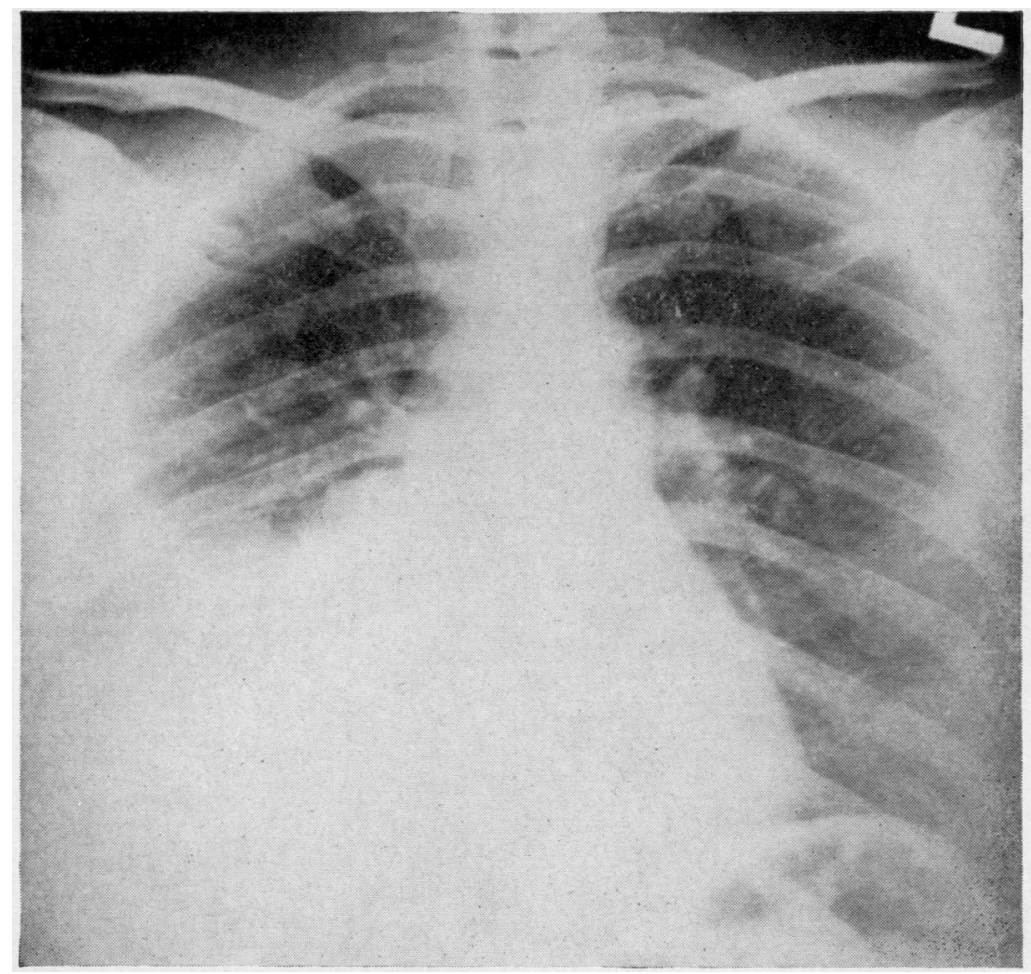

FIG. 14. Epidermoid thymoma. Lower part of right-sided pleural effusion with a mass arising low down from the anterior mediastinum. The growth was associated with myasthenia. Extensive but incomplete removal of tumour tissue (Fig. 2) was carried out. This was followed by radiotherapy. The patient died four years after operation.

liable to produce upper mediastinal pressure signs. Associated myasthenia is often acute in onset, but on several occasions the diagnosis of myasthenia was made only after pressure signs had been noted. This tumour has a slight predilection for men at a rather older age than most thymomas (15 men to 10 women), in contrast with lymphoepithelial tumour, which almost exclusively affects women.

Spread of the tumour is in saddle-formation over the ascending aorta on to the lung roots with implantation seedling deposits in the later stages. Spread to regional lymph nodes and into the supraclavicular fossae may occur, but distant metastasis was only once observed.

This type of tumour responds readily to irradiation. In four patients pre-operative therapy was used, in 10 patients it succeeded surgery, and in 11 it was not used. In this last group of 11 patients, two died post-operatively and the remaining nine are alive one to 10 years after operation for a localized tumour.

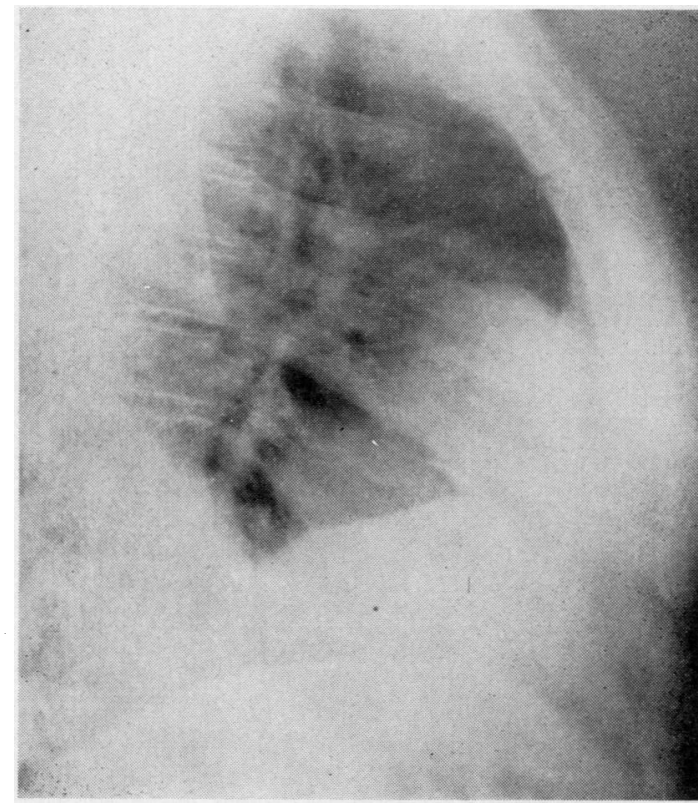


There were five fatalities, three directly consequent on the operation, one from pulmonary embolism a month later, and one from uncontrolled and progressive myasthenia.

Four patients died at a varying period after operation-two (four and five years later) from recurrence of the growth, one three years later from pneumonia and myasthenic exacerbation, and one 10 years later.

Of the survivors (16), two have recurrences in pleura three and four years after operation. The remainder over one to 10 years are clinically and radiologically normal.

In the myasthenic group those who survived operation have managed on a greatly reduced dose of neostigmine and six have stopped taking any drugs. The myasthenic symptoms have improved greatly, though occasional ocular disturbances and exacerbations have been recorded. These are usually associated with infection or undue fatigue.

Patients with severe bulbar symptoms have in recent years been treated with tracheostomy and been fed by oesophageal tube until they have regained sufficient strength to swallow satisfactorily. Several patients had to remain for some months in hospital before sufficient control was restored to permit them to lead a normal life.

ILlUSTRATIVE CASE In November 1950, E.S., a man aged 40, developed ptosis and diplopia with complete loss of control of all eye muscles and with difficulty in swallowing. Myasthenia gravis was diagnosed and he was treated with neostigmine. At operation an infiltrating hard mass was found. This was firmly adherent to the ascending aorta and was invading the left innominate vein. The tumour and adjacent tissues were excised en bloc, including the left innominate vein, to give adequate clearance.

The operation specimen consisted of pale tumour tissue measuring $5 \times 3 \times 3 \mathrm{~cm}$. On section the tissue was firm and white with some cystic areas and appeared only partially encapsulated. A lymph node, $2 \mathrm{~cm}$. in diameter, was submitted separately.

Histologically, the section showed an epithelial thymic tumour composed of large, well-differentiated, thymic, epithelial cells showing extensive Hassall's corpuscle formation (Fig. 3). There were three cases in this group in which Hassall's corpuscles were a feature of the histological picture. There was lymphocytic infiltration of varying density throughout the tumour tissue. The separately submitted lymph node was replaced by similar growth.

The patient received a post-operative course of deep $x$-ray therapy to a dosage of 5,529 r. and the myasthenia steadily improved, although he still required neostigmine but in diminished dosage. He recovered and returned to his duties, requiring a much lower dose of neostigmine. His progress was satisfactory for just over 10 years, when he was readmitted to hospital with asthenic symptoms that could not, however, be connected with myasthenia and he died from pneumonia.

\section{LYMPHO-EPITHELIAL THYMOMA}

(16 cases, 14 with myasthenia ; 13 alive and well, 3 dead)

This is basically the benign type of thymoma associated with myasthenia gravis. It is often unsuspected until the thymus gland has been removed and examined. The myasthenic onset is acute and oculomotor signs are invariably accompanied or followed by difficulty in swallowing and nasal speech. Weakness of the limb muscles is not as common as the bulbar signs.

Even with accurate radiology there may be no evidence of tumour, although anything larger in size than a walnut is usually recognized. In both non-myasthenic cases in this group the tumour reached a much bigger size (Fig. 15). This type of thymoma predominantly affects women in young adult life and middle age.

At operation one lobe of the thymus gland is found to be hard, enlarged, and adherent to surrounding structures. The mediastinal structures are not usually infiltrated and the regional lymph nodes are not involved.

The tumour is situated within the substance of the gland and is round or oval, with an apparent capsule (Fig. 16). The gland adjacent to the tumour is adherent almost to the extent of appearing to infiltrate extrathymic structures. On section the tumour is white, with occasional cystic and haemorrhagic areas.

Microscopically, there are the usual fibrous trabeculae enclosing the tumour cell masses. The large, pale, epithelial cells forming these masses are arranged as a loose network so densely infiltrated with lymphocytes that they are almost obscured and are with difficulty distinguished from reticulo-endothelial cells (Fig. 4).

Only two patients had post-operative radiotherapy, and then because there was some doubt as to the efficiency of the excision.

Though there is a good response to neostigmine in these patients, it is common to find that the dose is steadily increased until the patient is in a condition of severe neostigmine poisoning. Experience has suggested that positive pressure respiration with tracheostomy is a valuable pre-operative measure in treating the effects of overdose and preparing the patient for operation. Neostigmine can then be completely withdrawn and, when the 
FIG. 15. Lympho-epithelial thymoma. A large mass is situated anteriorly in the lower part of the right cheso The tumour had almost doubled its size in the course of 18 months after it was first noted. There was no sign of myasthenia and this is one of the two exceptions in this group. At operation there was no obvio $\overrightarrow{\mathrm{B}}$ connexion with the thymus gland. Removal was complete and there has been no recurrence over 11 years.

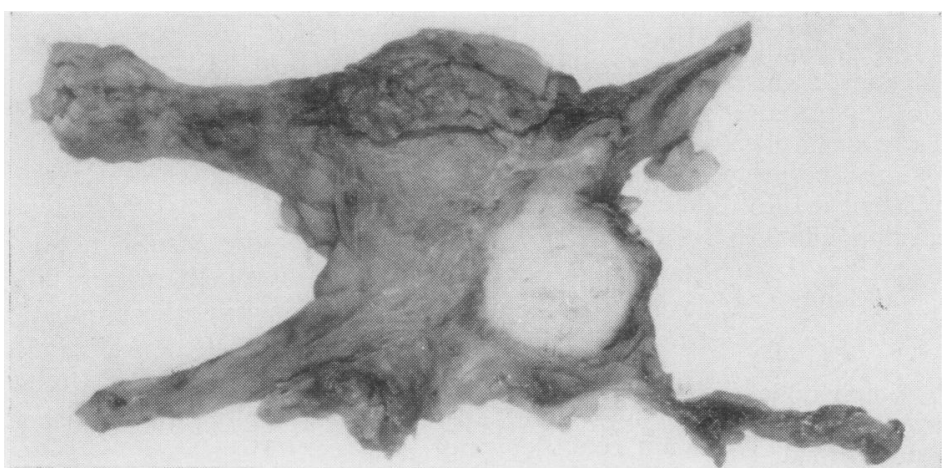

FIG. 16. Lympho-epithelioma. Tumour removed from a woman of 61 years with a short history of myasthenia gravis and a sudden onset. Marked relief of symptoms. The patient remains well three years later.

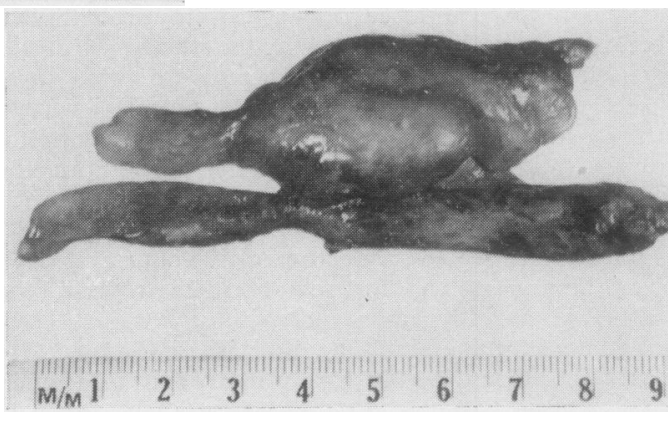


general condition is satisfactory, operation is undertaken and the patient is maintained on artificial breathing until he has sufficiently recovered to resume spontaneous respiration. $\mathrm{He}$ may still require neostigmine, though in a much smaller dose, and in five cases this drug has been given up completely.

There was one post-operative death from pneumonia in a patient with myasthenia gravis. There were two later deaths, one four years later in a patient with a diffuse tumour in whom myasthenic symptoms persisted. The other death was a young woman whose story is given (illustrative case E. P.).

No particular comment is necessary concerning the 13 survivors. The drug dosage has been considerably reduced in all patients and abandoned in five.

One patient (J. M.) was originally classified as a pure lymphoid tumour, but the reasons for changing her class to the rare non-myasthenic category are given elsewhere.

Illustrative CASE In March 1949, E.P., a young woman aged 24 , had a three-month history of acute myasthenia gravis with a nasal voice and weakness of all limbs. This was controlled by $30 \mathrm{mg}$. neostigmine every two hours. A chest radiograph showed an oval tumour in the anterior mediastinum (Figs 9a and $b$ ).

At operation a vertical, sternal-splitting incision was performed and a tumour attached to the lower pole of the right lobe of the thymus was removed. This tumour was not included within the gland as it is in most cases.

The thymectomy specimen consisted of an encapsulated mass which measured $8 \times 5 \times 3 \mathrm{~cm}$. and was composed of firm, pale, homogeneous tissue.

Histologically, the tumour tissue was composed of a uniform mixture of lymphocytes and large, palestaining thymic epithelial cells. The appearances were those of a thymic lympho-epithelioma. The capsule appeared intact.

After leaving hospital the patient improved on a considerably reduced dose of neostigmine. Subsequently she required no drugs. She married, and a pregnancy had no deleterious effect on the myasthenia gravis. In January 1951, when out shopping, she became suddenly weak and fell down in the street. She was taken to hospital, where, unfortunately, the nature of her condition was not recognized and no neostigmine was given. She developed pneumonia and died. At necropsy there was no recurrence of the tumour. It is presumed that her collapse was due to a sudden crisis or onset of the myasthenic process which had been quiescent for two years. Since she was not given the appropriate drugs the clinical proof is lacking, but sudden, unexpected crises are not unknown even after a long period of freedom from symptoms.
OVAL AND SPINDLE CELL EPITHELIAL TUMOURS (16 cases, 3 with myasthenia; 12 alive and well, 4 dead)

These two tumours are histologically distinct but similar in nearly all other respects. The tumour in which the epithelial cells are oval in shape and arranged in whorled formations has been referred to as the 'classical' thymoma. The spindle-cell tumour has in the past been confused with a sarcoma. Without experience of the age changes in the normal thymic epithelioma it is difficult to believe that this is an epithelial tumour (Fig. 6). Both types of tumour are usually discovered accidentally on radiography and take the form of a small rounded or oval-shaped tumour which is well encapsulated (Figs 17 and 18). Their behaviour is essentially benign.

At operation removal is straightforward, as the tumour has minimal adherence to the lung and an indefinite fibrous pedicle with few blood vessels attached to the region of the anterior part of the aortic arch. An actual connexion with the thymus gland cannot always be established.

Of the four deaths, none was related to the operation, two patients died of cardiac infarction (three and five years later), and one of pneumonia. The remaining death was attributed to a recurrence three years later, and this was the only case with a recurrence. The three myasthenic patients did well and require minimal medication. The longest survival is 13 years.

Radiotherapy was used post-operatively on only one myasthenic patient.

ILlUSTRATIVE CASE An incidental chest radiograph of L.H., a man aged 60 , showed a small opacity against the left upper mediastinum. Investigation could not determine whether this was pulmonary or mediastinal. There were no symptoms.

In 1960 a left thoracotomy was performed and an oval mass firmly adherent to the lung and with a vascular pedicle leading towards the lower pole of the thymus was excised.

The specimen consisted of an irregularly lobulated, firm tumour mass, $7 \times 6 \times 5.5 \mathrm{~cm}$., having a fibrous covering at one end continuous with an attached mass of fibrous tissue, $7 \times 7 \times 3 \mathrm{~cm}$. At the other pole of the tumour some fatty thymic tissue was present. On section, the tumour was solid, pale pink in colour, and apparently encapsulated (Fig. 19). Microscopically, it was made up of whorled masses of more or less oval epithelial cells with only very occasional mitoses. The lymphocytic infiltrate varied in amount in different parts of the tumour but was nowhere dense (Fig. 5).

The patient remains well and active six years later. 


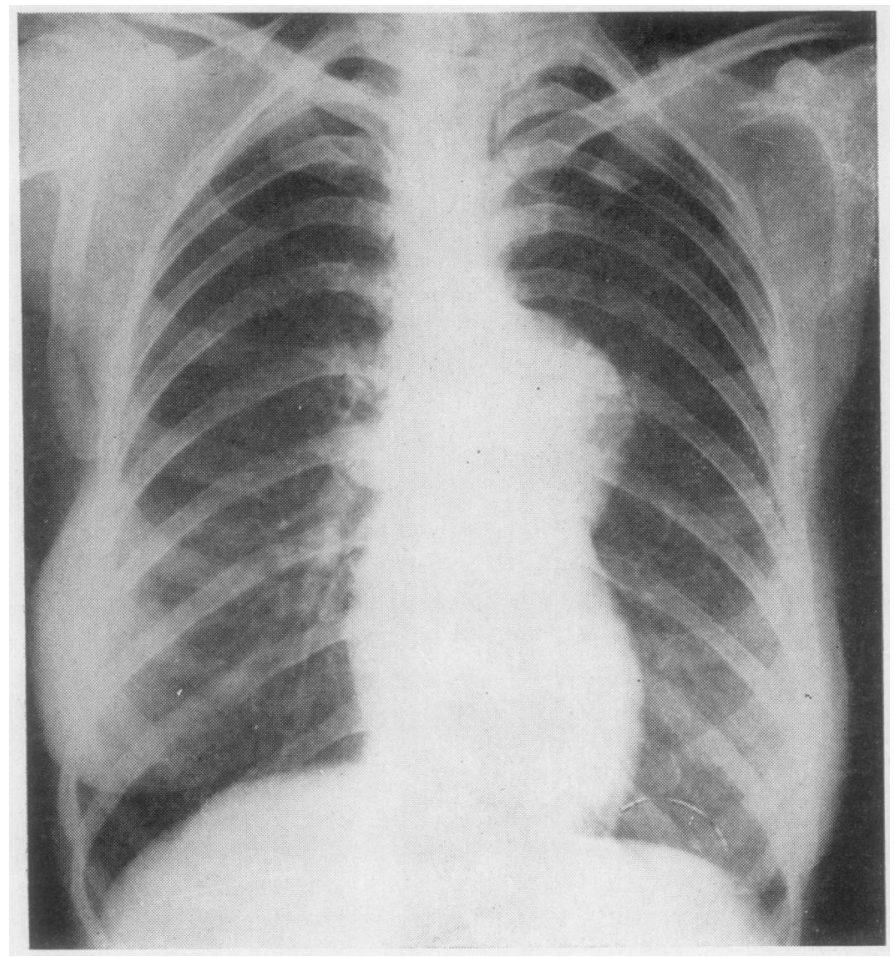

FIG. 17. Spindle-cell thymoma. Mass, with smooth outline extending into this left lung field. After removal the originat diagnosis was lymphosarcoma.
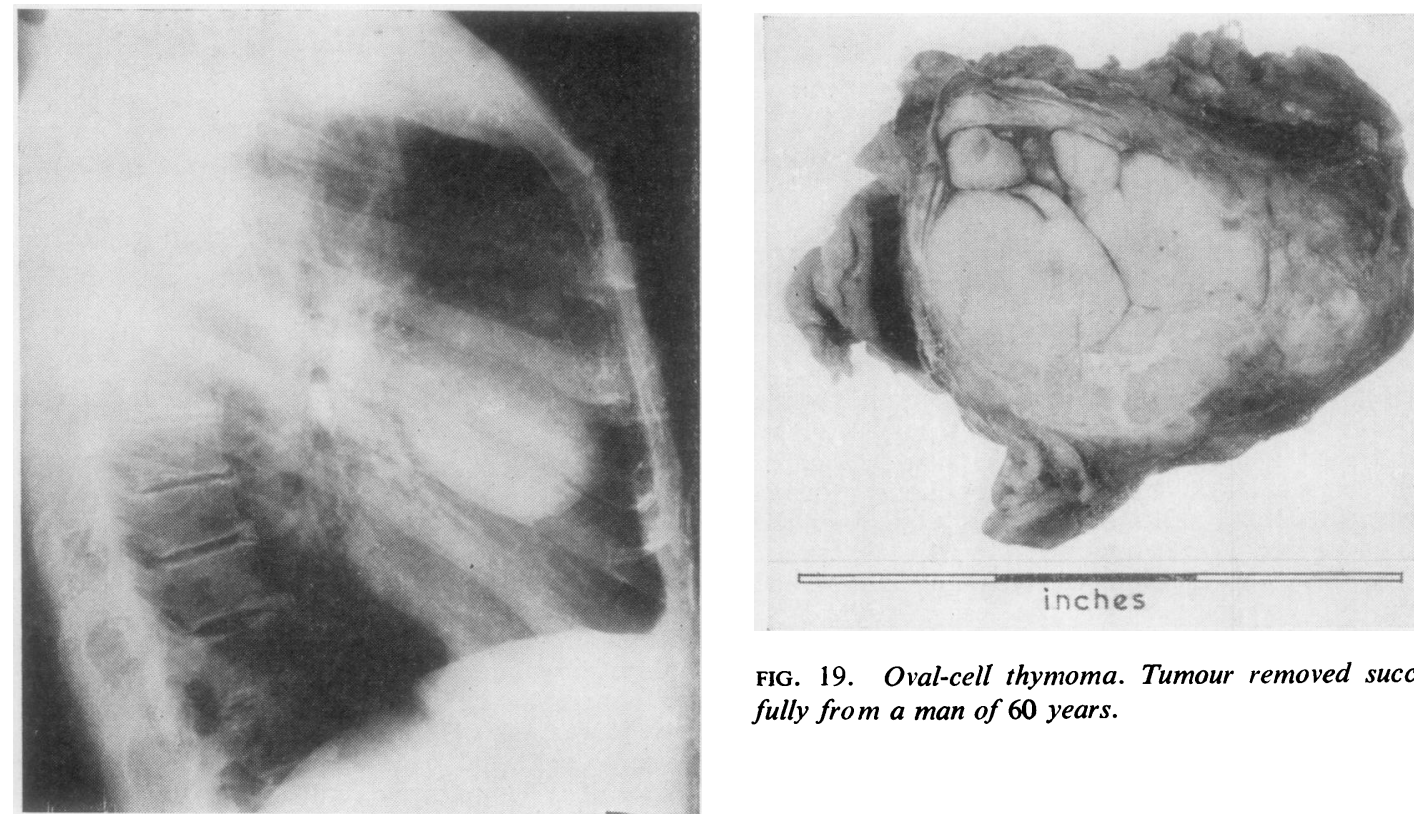

(⿸丆口

FIG. 19. Oval-cell thymoma. Tumour removed successfully from a man of 60 years.

FIG. 18. Oval-cell thymoma. Rounded shadow arising from the anterior mediastinum. Treated by excision. 
GRANULOMATOUS THYMOMA

(17 cases, 1 with myasthenia ; 10 alive and well, 7 dead)

These cases undoubtedly form the most interesting and debatable group pathologically. Although 15 years have passed since Lowenhaupt and Brown (1951) stated 'carcinoma of the thymus of granulomatous type has recently been clearly segregated from Hodgkin's disease of this area', the histological distinction is still often difficult to make, even when guided by their criteria. In addition to the histological similarities both conditions extend to involve nearby lymph nodes.

Six patients were 25 or under and only three were over 40 , and there was a preponderance of women over men of two to one. This tumour was associated with myasthenia in only one instance.

At operation it is not possible to separate or find a clear line of demarcation between the thymus itself and the pathological granulomatous area, for the granulomatous thymoma is an infiltrating and invasive tumour of the medias- tinum extending freely into one or other (sometimes both) lung fields, giving pressure signs and symptoms. Radiologically, the mass is ill-defined, but it originates in the mediastinum and, for this reason, gives pressure signs in many cases.

There is a tendency for the growth to extend lower in the chest than the thymus gland area, and with lateral extension it frequently infiltrates the superior vena cava and right phrenic nerve and spreads over the lung roots (Figs 20a, b, and c). It may also invade lung to a much greater extent than any other infiltrating thymoma, and in two instances a formal lobectomy had to be undertaken.

The decision as to the plan of treatment varies with each individual case. A small more or less localized tumour is probably treated in the first instance by surgery and then, when the nature of the tumour is defined, by irradiation. Apparently complete excision was possible in five patients, and in two of these radiotherapy had not been used.

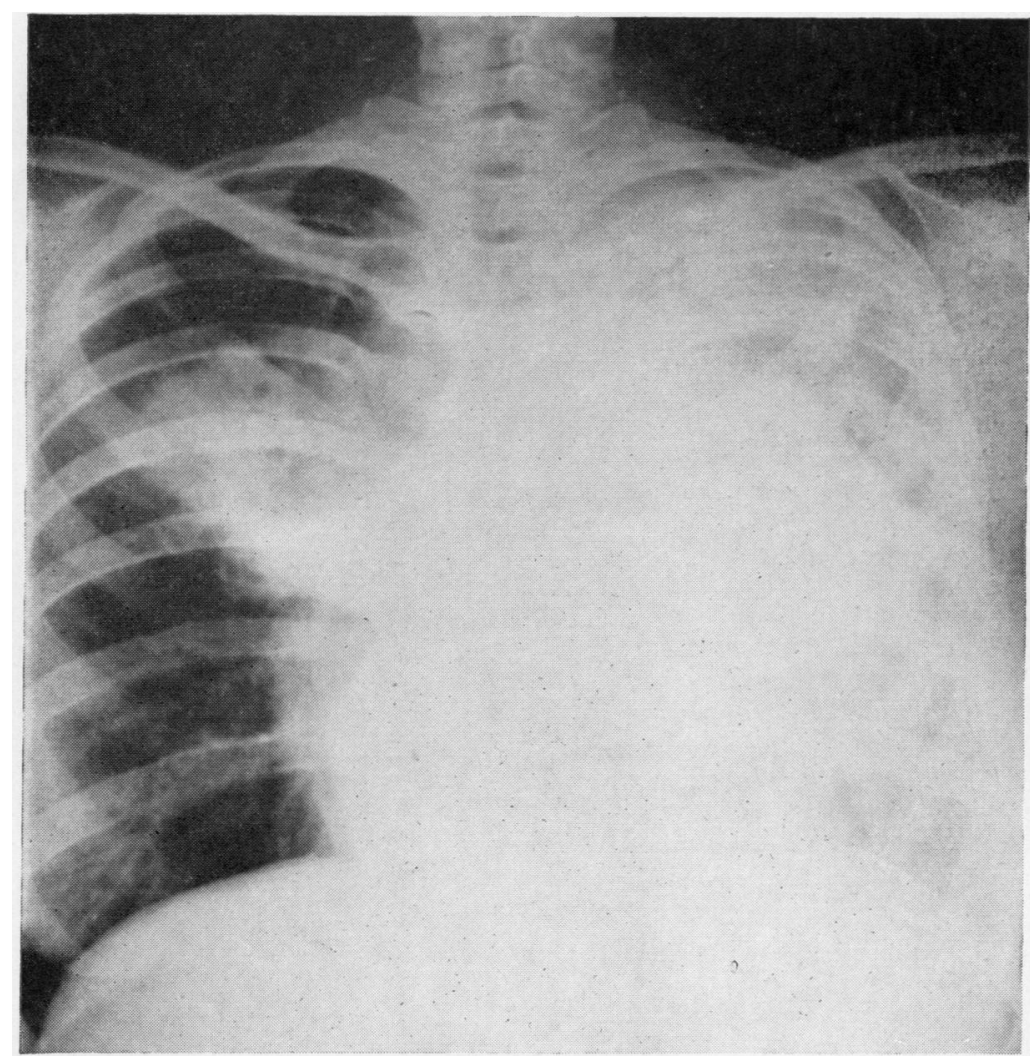

FIG. 20a. For legend see p. 212. 


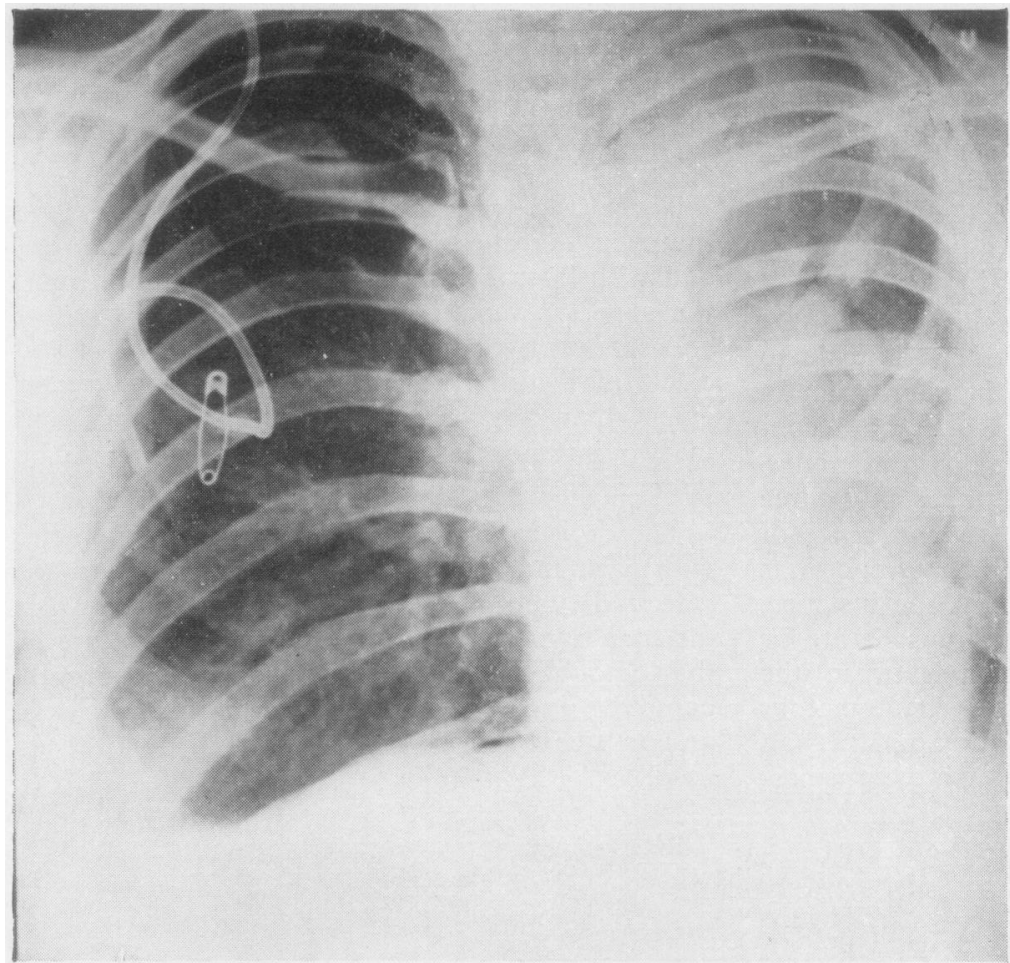

FIG. 20b

FIGS 20 a, b, and c. Granulomatous thymoma. A woman aged 34 years. Radiological opacity involves most of the left lung, with a more localized mass in the right lung field. Right exploratory thoracotomy allowed partial excision of the mass, which extended across the mediastinum. Microscopy showed a granulomatous thymic tumour (Fig. 7). Radiotherapy followed and the patient has remained well for 14 years.

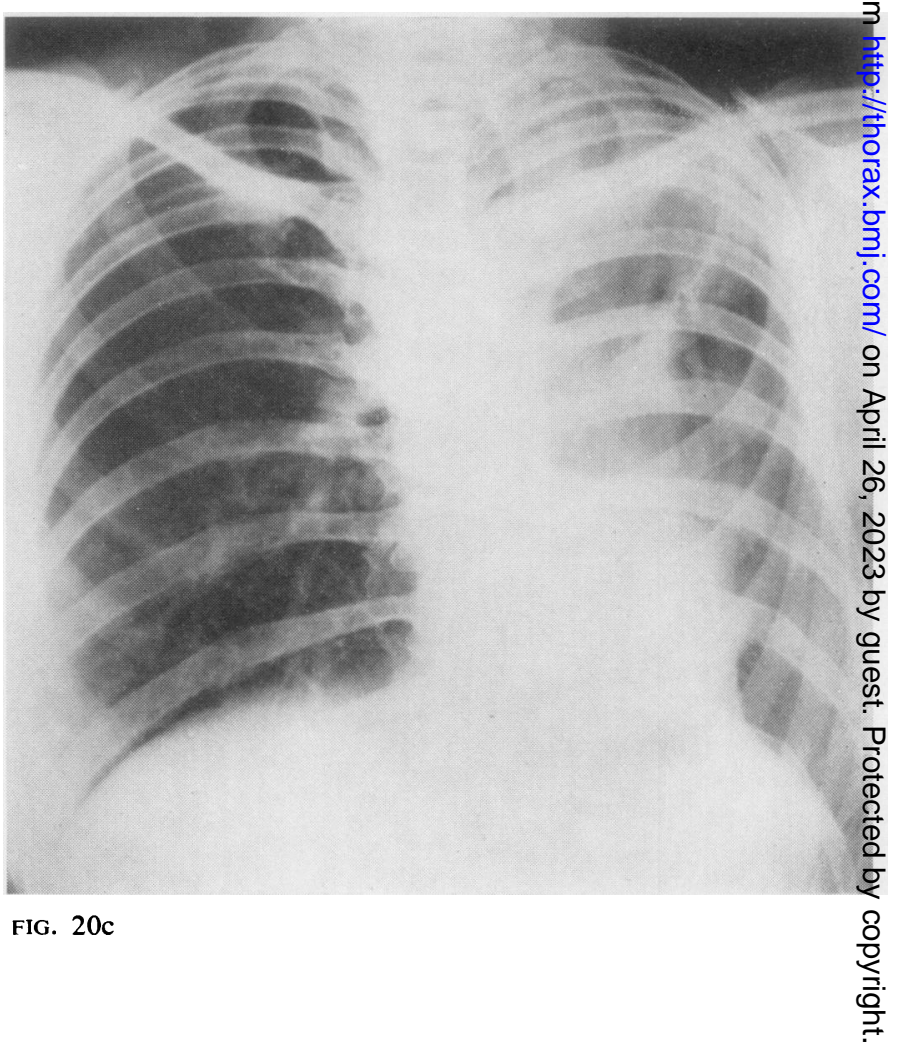




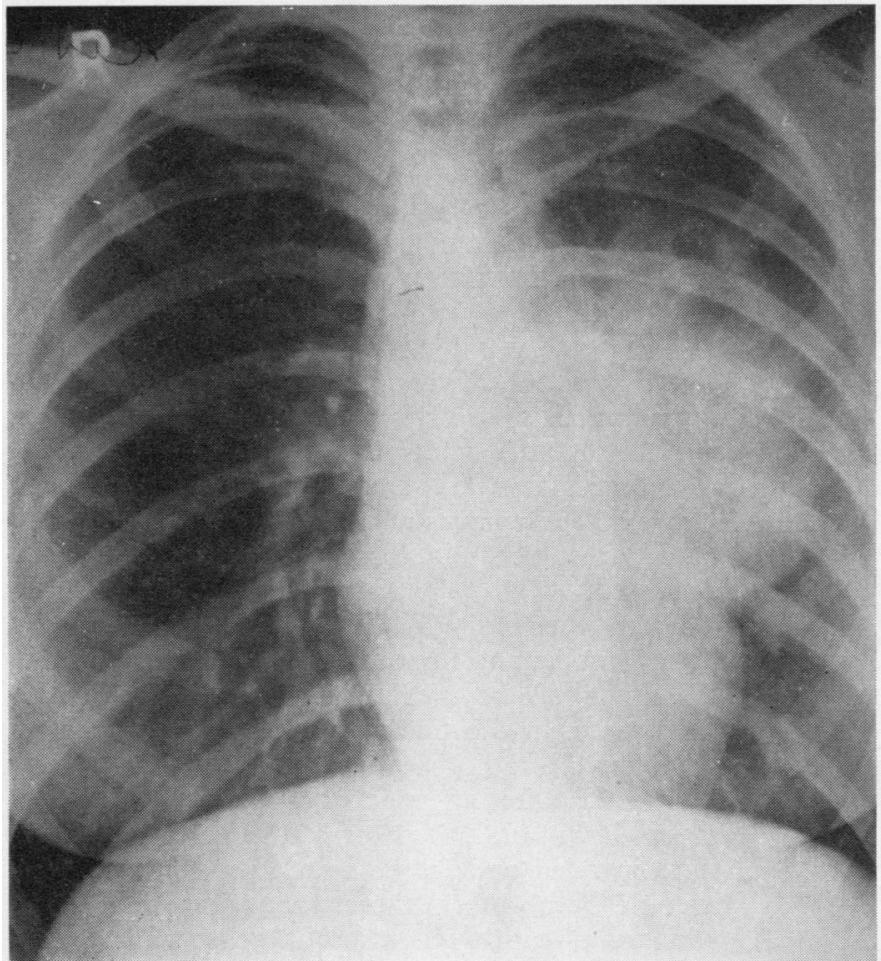

FIGS 21 a and b. Granulomatous thymoma. A young woman aged 21 years. Tumour invaded the left lung and at operation the mediastinal growth with the left upper lobe was removed. Six months later the patient developed secondaries in the opposite lung. Radiotherapy was administered with radiological and symptomatic improvement. The patient died three and $a$ half years later.

FIG. 21a

Where there is evidence of a more diffuse tumour, preliminary irradiation may achieve considerable reduction in tumour size before surgery is undertaken. This occurred in four patients, and in three of these a complete excision was achieved.

The actual figures for the use of radiotherapy are: pre-operatively in four, post-operatively in 11, not used in two patients. It is probable that some additional cases are included in the nine under the heading 'irradiated' tumours. In the early years a good deal of disability was encountered as the result of lung fibrosis following radiotherapy. This is now minimal. Where the pathology has been satisfactorily established the field of radiation should cover not only the mediastinum but also the regional gland areas.

There were no post-operative deaths, but later deaths accounted for seven patients who died one to nine years after operation. Four of these died within four years, two with distant metastases. Two died seven years later without recurrence, and one died nine years later from a carcinoma of the breast.

The longest survival periods are one of 11 , one of 12 , and one of 13 years. This includes the only

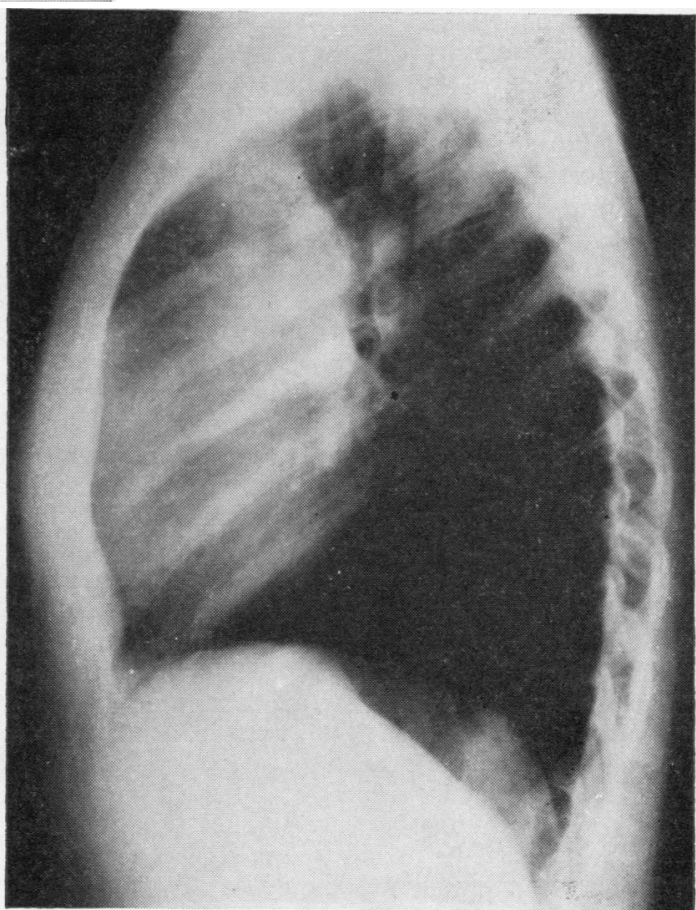

FIG. $21 b$ 
myasthenic patient in whom the excision was incomplete.

The clinical and pathological features in these tumours are often sinister in the first instance, but there is some satisfaction in the fact that six patients have lived more than seven years after operation.

ILlUStrative CaSes (a) In September 1952, J. R., a nursing sister aged 25 , who was asymptomatic, had a routine chest radiograph and was found to have a mass the size of a walnut in the anterior mediastinum. This mass was suspected of being inflammatory as it became smaller radiologically. A further chest radiograph in June 1954 showed a larger mass at the same site. This was diagnosed as a thymic tumour.

A left thoracotomy was performed and a tumour was found in the region of the left lobe of the thymus. It was adherent to the lung and was infiltrating the left innominate and subclavian veins. A wide excision, which included lung and the junction of the left innominate and subclavian veins, was performed.

The specimen consisted of pale, firm tissue, measuring $5 \times 4 \times 4 \mathrm{~cm}$., with an adherent portion of a blood vessel and lung tissue.

Microscopically the thymus gland was replaced by a granulomatous mass in which there was fibroblastic tissue containing large mononuclear cells and giant cells, some of which were binucleate and others which contained up to six nuclei. In addition there was a diffuse infiltration by polymorphonuclear leucocytes, eosinophils, and some lymphocytes. The intervening areas consisted of mature fibrous tissue with scarcely any cell type present. The appearances were those of a granulomatous thymoma.

The post-operative course was uneventful and was followed by a full course of irradiation. The patient resumed her nursing duties and remains well 12 years later. The radiological appearances are satisfactory and she is free from any symptoms.

(b) A.S., a young married woman aged 21 from overseas, had suffered from cough and shortness of breath, as a result of which she had a chest radiograph. There was a large lobulated mass extending widely from the upper mediastinum into the left lung field (Figs 21a and b). A short course of radiotherapy was given, but without any marked effect.

A left thoracotomy was performed and a large tumour extending from the anterior mediastinum into the left upper lobe was exposed. Following an extensive dissection the mass in the mediastinum was freed, and with excision of the left upper lobe all obvious signs of tumour were removed.

The microscopical appearances of the tumour were typical of a granulomatous thymoma not dissimilar to the features of the previous case.

During the subsequent six months the patient had occasional haemoptyses which ceased on removal of loose sutures from the bronchus stump.

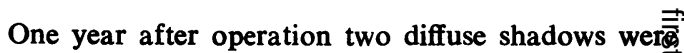
noted in the right lung and a course of radiotherapt was begun. The patient remained well for anothef year, but with a progressive increase in the size and number of recurrences in the lung fields there was increasing shortness of breath. The patient diea three and a half years after operation.

\section{UNDIFFERENTIATED CARCINOMA \\ ( 2 cases, none with myasthenia ; both dead)}

There are only two examples of this form of thymoma in this series, though further instances may be included under the heading of "irradiated thymoma. It is not associated with myastheniz gravis and it behaves in contrast with the differenfs tiated or epidermoid form that has already beet discussed.

From the limited evidence available it is highly malignant tumour which spreads beyond the limits of the mediastinum and gives rise to metastases. In the one patient who was operated on following radiotherapy the upper mediastinum was filled with an amorphous, hard, yellowis mass without outline or form. The aorta and lungs were invaded and from the extensive biopsy (fom it could be no more) there were areas of necrosio and zones of thymic tumour cells which were presumably viable. This patient died from distan metastasis in the liver one year after irradiation and exploration.

The general impression from the literature is that the truly undifferentiated thymoma is highl伊 malignant, gives rise to early local and distant metastasis, and is not compatible with survivat over a period of one year.

\section{LYMPHOID TUMOURS}

Lymphoid tumours of the thymus are rare and are usually associated with involvement of othes lymphoid tissues or with a leukaemic bloo pressure and so are not surgical problems. Histo@ logically, the picture is identical with that of similar tumours elsewhere. The tumour celif masses are prone to undergo necrosis and lack the fibrous trabeculation seen in nearly all other thymic tumours. Thomson and Thackray (195fof reported 10 of these tumours; nine were rapidl fatal and were only identified in the thymus posit mortem. Their tenth case, now thought to have been misdiagnosed, is described below (J. M.).

A rare and curious condition occurring in the mediastinum has been called 'giant hyperplasia of lymph nodes'. If it affects the anterior mediase tinum the smooth rounded shadow seen in the 


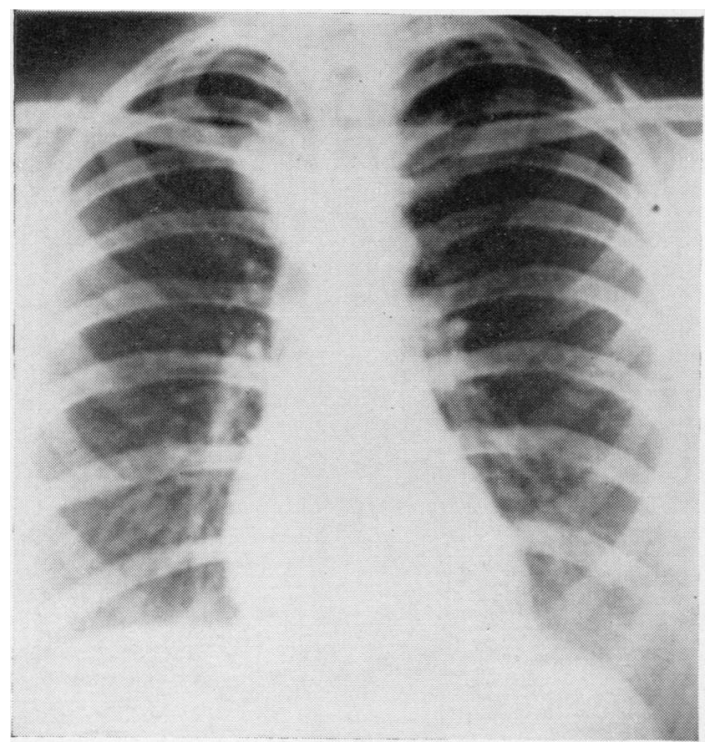

FIG. 22. Tumour situated in the posterior mediastinum. This was removed easily. Survival without symptoms for 14 years.

radiograph may be mistaken for a thymoma, whilst the surgically removed specimen is liable to be diagnosed histologically as a lymphoma and regarded as of thymic origin. A number of these tumours have been included in series of thymic tumours in the past. One such tumour which was surgically removed during the period of the present study showed the characteristic features described by Castleman, Iverson, and Menendez (1956) (Fig. 22).

The following case note is not illustrative of a classical lymphoid thymic tumour but indicates the difficulties that may be encountered in making a histological diagnosis.

ILLUSTRATIVE CASE One month before admission to hospital J.M., a woman aged 51, developed pneumonia and pleurisy which responded to treatment. Radiography showed an effusion and a rounded opacity associated with the right border of the heart. Subsequent investigations suggested that this mass was extrapulmonary, possibly a cyst of the pericardium or a dermoid (Figs 23a and b).

Operation was undertaken in 1953 by Mr. C. W. James. A right thoracotomy was performed, and a globular mass larger than a grape-fruit was dissected from the middle lobe and the diaphragm. Its root extended centrally and upwards to the region of the thymus gland, most of which was removed with the tumour.

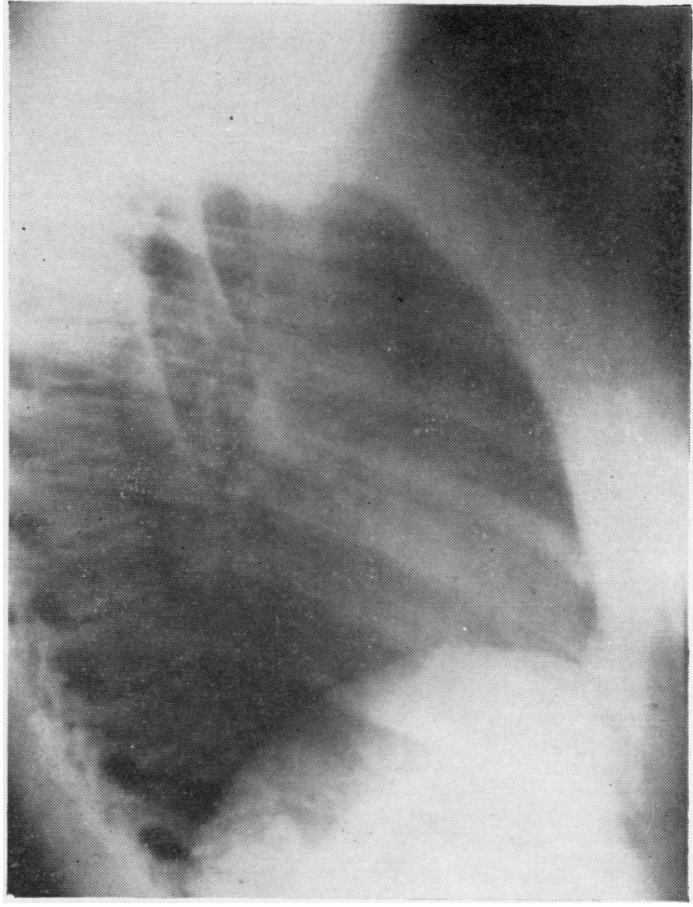

The patient made an uneventful recovery and has remained alive and well for 13 years.

Microscopically there was extensive necrosis in the tumour mass, and as a result of delay in fixation the tumour was ill-preserved. It was diagnosed at the time as lymphosarcoma, but with the subsequent history of the case in mind, and with further experience of the effects of autolysis on the epithelial cells of the lympho-epithelial thymoma, on reviewing the sections there is now little doubt that this was an example of that tumour type.

\section{TERATOMATOUS THYMOMA}

( 2 cases, none non-myasthenic; both dead)

Mediastinal teratoma is an accepted entity, but there are some instances in which the tumour must be regarded as being of thymic origin on account of the complete admixture of thymic and teratomatous elements within a malignant mass lying in the situation of the normal thymus gland. All three germinal layers and thymic tissue are represented in a confused manner. Both patients were men.

The clinical features are those of a rapidly growing malignant tumour in the anterior mediastinum. It extends well into one or both lung fields and gives acute signs of mediastinal pressure. Widespread metastases are common. 
These tumours are extremely radiosensitive and respond dramatically to radiotherapy, only to return or metastasize within a few weeks or months following treatment. In the two patients submitted to surgery complete excision was impossible, and in spite of a full course of radiotherapy after operation both died within a few months.

ILlUSTRATIVE CASE Six weeks before admission $H$. B., a man aged 35, coughed up bright blood. This persisted and was accompanied by shortness of breath.

On examination there was visible pulsation in the left side of the chest anteriorly, and this was associated with a large rounded opacity in the anterior mediastinum. The most likely diagnosis appeared to be a dermoid cyst, but further investigations were not informative although blood-stained fluid was aspirated from the left chest.

A left thoracotomy was performed and 31 . of blood-stained fluid were removed. In the upper mediastinum there was a $15 \mathrm{~cm}$. diameter mass infiltrating the pleura and left upper lobe of the lung as well as the pericardium. This mass was incised and a considerable volume of necrotic tissue was evacuated. It was not possible to remove the tumour.

Radiotherapy was given post-operatively, but the patient's condition deteriorated and he died five months after operation.

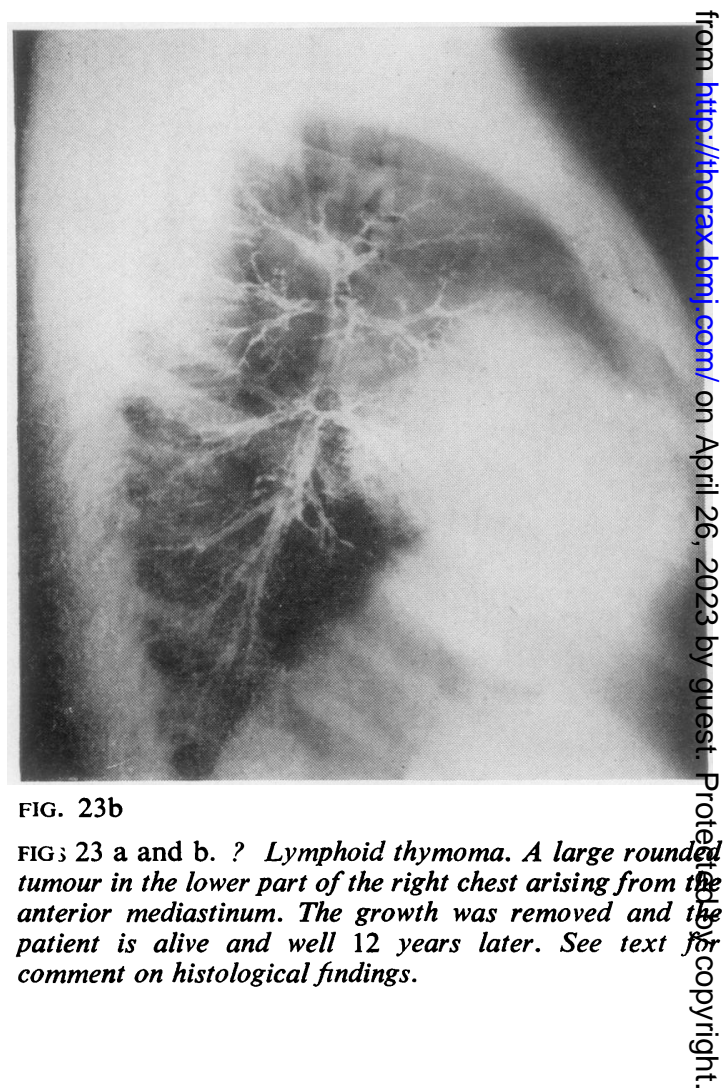


The operation specimen consisted of two friable and irregular pieces of tissue, $5 \mathrm{~cm}$. and $2.5 \mathrm{~cm}$. in diameter. On section the tissue appeared to be largely necrotic, but there were firm white areas at the centre.

Microscopically the sections showed a malignant teratomatous picture with a spindle-cell stroma in which there were many areas of malignant epithelial tissues of various types but showing predominantly squamous epithelial and glandular carcinomatous areas (Fig. 1).

\section{UNIDENTIFIED TUMOURS}

(10 cases, 1 with myasthenia; 7 alive and well, 3 dead)

From Tables I to III it will be seen that some thymic tumours irradiated before removal were so little affected histologically that they could still be satisfactorily classified. A number of tumours in the series, however, were so changed by this treatment that they could not be confidently assigned to any of the groups so far named. Some

T A B LE I

\begin{tabular}{|c|c|c|c|c|c|}
\hline \multicolumn{6}{|c|}{ MYASTHENIC THYMIC TUMOURS } \\
\hline Tumour & Total & $\begin{array}{l}\text { Hos- } \\
\text { pital } \\
\text { Death }\end{array}$ & $\begin{array}{l}\text { Later } \\
\text { Death }\end{array}$ & Survival & Comment \\
\hline Epidermoid & 19 & 2 & 6 & $\begin{array}{l}8>3 \text { yrs } \\
3<3 \text { yrs }\end{array}$ & $\begin{array}{l}11 \text { had D.X.R. } \\
\text { Of the } 6 \text { deaths: } \\
2 \text { recurrence } \\
2 \text { incidental } \\
2 \text { myasthenia }\end{array}$ \\
\hline $\begin{array}{l}\text { Lympho- } \\
\text { epithelial }\end{array}$ & 14 & 1 & $\begin{array}{c}2 \text { myas- } \\
\text { thenia } \\
\text { gravis }\end{array}$ & $\begin{array}{l}63 \text { yrs }+ \\
5<3 \text { yrs }\end{array}$ & $\begin{array}{l}6 \text { needed no } \\
\text { drugs } \\
2 \text { had only } \\
\text { D.X.R. }\end{array}$ \\
\hline $\begin{array}{l}\text { Oval cell } \\
\text { Spindle cell } \\
\text { Granulo- }\end{array}$ & $\begin{array}{l}1 \\
2\end{array}$ & \} 0 & 1 heart & $1>3 \mathrm{yrs}$ & 1 had D.X.R. \\
\hline $\begin{array}{l}\text { matous } \\
\text { Irradiated }\end{array}$ & $\begin{array}{l}1 \\
1\end{array}$ & $\begin{array}{l}0 \\
1\end{array}$ & $\frac{0}{-}$ & 16 yrs & Post-op. D.X.R. \\
\hline Total & 38 & 4 & 9 & $\begin{array}{l}16>3 \text { yrs } \\
12>5 \text { yrs }\end{array}$ & 16 had D.X.R. \\
\hline
\end{tabular}

\section{T A B L E I I I}

RESULTS

\begin{tabular}{l|c|c|c|c|c|c}
\hline Tumour & Total & $\begin{array}{c}\text { Hos- } \\
\text { pital } \\
\text { Death }\end{array}$ & $\begin{array}{c}\text { Late } \\
\text { Death }\end{array}$ & D.X.R. & Alive & \\
\hline $\begin{array}{l}\text { Myasthenic } \\
\text { Non-myas- } \\
\text { thenic }\end{array}$ & 38 & 4 & 9 & 16 & 25 & 16 lived >3 yrs \\
\hline Total & 88 & 2 & 12 & 28 & 36 & 21 lived >3 yrs \\
\hline
\end{tabular}

were entirely necrotic; in others, only small groups of surviving tumour cells were found (Fig. 8). These tumours have therefore been grouped together as 'unidentified irradiated thymic tumours', though from their behaviour it seems likely that most of them were granulomatous or undifferentiated epithelial growths.

Two patients under this heading died within 18 months from recurrence, one with distant metastasis. One surviving patient is worthy of record. A young woman of Mediterranean stock had had severe mediastinal pressure signs and symptoms with obvious superior vena caval obstruction. The original radiological report described a widespread shadow situated anteriorly over both lung roots. She was irradiated and gained some improvement in that the venous engorgement of the head and neck was not so prominent. Operation was undertaken through an anterior bilateral thoracotomy, and a mass of whitish tumour tissue was excised from the root of the neck down to the diaphragm, including the left innominate vein, the pleural margins with fringes of lung in the anterior parts of the thorax, and the whole anterior pericardium. Some infiltrating tissue on the anterior aspects of the lung roots could not be cleared.

Recovery was without incident. Subsequently the patient married and had two children. She was

T A B L E I I

NON-MYASTHENIC THYMIC TUMOURS

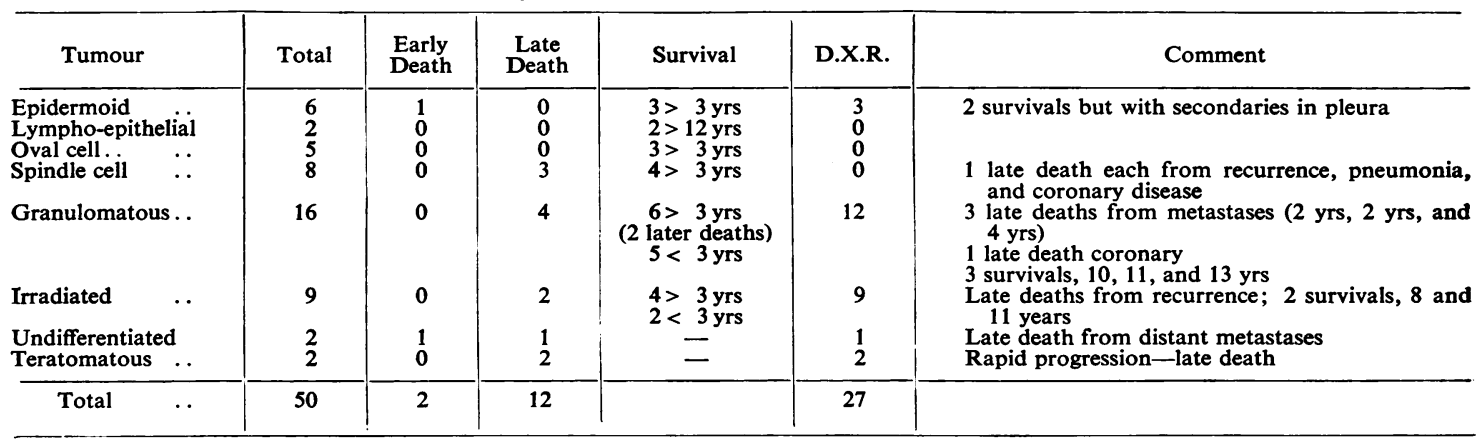


last seen alive and well and without symptoms seven years after the operation.

Against this apparently dramatic recovery must be set the case of a middle-aged man who had severe symptoms of myasthenia gravis. He was admitted to hospital in this country after a course of irradiation. He was unable to swallow and had to take anti-cholinesterase drugs by injection only. An operation was performed and an extensive resection of all apparent tumour was carried out. This excision included not only the thymus but the anterior pericardium, pleural margins, and a part of the lung. A tracheostomy was performed and all drugs were withheld until controlled respiration could safely be given up. The recovery was dramatic. Normal swallowing and normal vision were restored, and on a minimal dosage of neostigmine the patient was able to walk about. $\mathrm{He}$ was able to move about unaided within three weeks of the operation and was ready to leave hospital when he was found dead in bed. In the absence of a necropsy it is not known whether a pulmonary embolus or a sudden myasthenic crisis was responsible. The microscopic appearance of the tumour suggested that it had been an epidermoid thymoma, but it was too extensively altered by irradiation for definite diagnosis.

\section{DISCUSSION}

Tumours of the thymus gland are pathologically confusing and difficult to classify. The macroscopic appearances can only give an approximation as to the type of histology which will be encountered. Thus an encapsulated tumour which is obviously attached to the substance of the thymus gland may prove to be a differentiated epithelial thymoma, a spindle-cell thymoma or a lymphoepithelial thymoma. A necrotic tumour with evidence of invasion of adjacent tissues usually proves to be a granulomatous thymoma, an undifferentiated epithelial growth, or a teratoma.

The classification which we have adopted is based on the predominant histological features that are present in a number of different fields within the tumour. We are aware of different methods of classification which have been proposed by many authors, including Lowenhaupt (1948), Iverson (1956), and Lattes (1962), but since the publication of our classification in 1957 we have found that all subsequent cases which we have examined have fitted well into our proposed scheme. Accordingly, we have used this method of classification although recognizing that other authorities may prefer different sub-divisions.
Our classification does provide an approximate $\overrightarrow{\vec{F}}$ correlation between the histology and clinical $\frac{}{0}$ course of any given case. Thus the patient with myasthenia gravis will usually prove to have a के relatively benign lympho-epithelioma or the $\mathbb{\otimes}$ slightly more malignant epidermoid thymoma.

Oval and spindle-cell tumours tend to be localized and slow-growing, with little infiltration and no distant metastases. The majority of these $\overrightarrow{\vec{\omega}}$ are non-myasthenic and have a good prognosis. $\stackrel{\sim}{\circ}$

At the other end of the scale are the undifferen- $\overrightarrow{\vec{x}}$ tiated epithelial thymoma and teratoma. These i are both highly malignant and, in spite of a good $N$ early response to irradiation, they recur and are rapidly fatal.

Surgery and radiotherapy in the semi-malignant 음 forms (epidermoid and granulomatous) give variable results which are sometimes remarkably $\$ successful, though it is difficult to predict which cases will respond favourably.

The policy of an aggressive treatment in all forms of mediastinal tumour appears to be well founded. Radiotherapy alone has yet to prove its full worth, but if used in combination with surgery it achieves many good results. Surgery by itself is adequate in localized tumours, $\frac{\circ}{\mathbb{Q}}$ particularly in the spindle-oval forms and in lympho-epithelioma, but wherever infiltration is $\overline{\overrightarrow{0}}$ encountered the addition of radiotherapy is advisable.

One of the intriguing features of those thymomas which tend towards malignant be- $\overrightarrow{0}$ haviour is the relative absence of distant metastases, though regional gland invasion and implantation secondaries are relatively common.

The myasthenic tumours provide one of the most fascinating and as yet unsolved fields in modern medicine. The thymus is a not insignifi- 0 cant gland undergoing marked involution changes? during the development of the body as a whole. $\frac{7}{0}$ Yet little is known about its purpose or function. When a functional disturbance does occur the $N$ gland is often associated with myasthenia gravis, $N$ where the pathological changes in most cases are N simply those of general hyperplasia and an increase in the germinal follicles. Removal of the gland does alleviate myasthenic symptoms and may even cure them, but the mechanism is still not clear. One view is that the gland has produced ${ }_{7}^{+}$ a secretion of a curare-like nature that acts as a competitive blocking agent on the motor end- $\vec{\Phi}$ plates.

The ocular muscles are almost always affected $\stackrel{\odot}{\circ}$ and, to a varying extent, the general skeletal

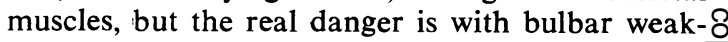


ness, where palatal and mastication muscles are involved and feeding becomes not only difficult but dangerous because of the risk of the inhalation of liquids and food. The suggestion that myasthenia is an auto-immune disease and related to a whole host of other auto-immune conditions has its advocates, but in our experience full proof of this thesis is lacking.

When a thymic tumour is present in myasthenia the epithelial element is probably the dominating factor. The onset of the myasthenia is sudden and severe, and whereas it may be controlled for a time by anti-cholinesterase drugs, bulbar weakness with its complications provides a strong indication for surgery. Many authorities have advocated radiotherapy as an initial step in treatment, and indeed with an infiltrating tumour this may be the correct course, but our figures suggest that primary excision serves many of these cases adequately, but if there is any doubt as to the efficacy of the excision post-operative irradiation is indicated. Again, contrary to some expressed views, these myasthenic tumours do reasonably well and derive considerable benefit from treatment, some to such a degree that they can give up drugs altogether. On the other hand, the inexplicable behaviour of myasthenia gravis cannot be ignored. Six patients died with uncontrolled myasthenia or from an unexpected exacerbation, pneumonia being the terminal feature. This was out of a total of 11 who died between the post-operative period and 10 years.

A certain amount has been written about the development of myasthenic symptoms after thymectomy for a tumour. We refute the statement that all patients who have a thymoma will develop this disorder sooner or later. Myasthenia did develop in one patient who had had a mediastinal tumour, later proved to be a thymoma. The mediastinum was re-explored but no further tumour or residue of the thymus gland was found. Examination of the history and the investigations, which included bronchoscopy, showed that the patient's response to muscle relaxants was abnormal in that recovery from anaesthetic was very prolonged. Many anaesthetists are unhappily aware of the effects of these drugs in patients in whom myasthenia gravis and myasthenic-like conditions have not been recognized. Lambert and Rooke (1965) record 30 cases of a myasthenic syndrome associated with cancer of the lung (small or oat-cell type). Twenty-two of these had definite lung tumours and there was improvement after lung resection in some patients. They state that this has no connexion with thymoma or any other form of carcinoma and that the transmission in the neuro-muscular system differs from that of true myasthenia gravis by showing a block or delay in the rested muscle but facilitation in active muscle. Thymoma is, however, said to be found in polymyositis, but it is difficult to be certain to what extent the pattern differs from that of myasthenia gravis.

Among the non-myasthenic thymomas the granulomatous form is undoubtedly the most interesting. These tumours arise from the thymus gland and have been described fully from the histological aspect by Lowenhaupt and Brown (1951), Thomson and Thackray (1957), and more recently by Lattes (1962). The accounts are very similar and if the basic cell is reticulo-endothelial the tumour should be regarded as a type of epithelial thymoma rather than Hodgkin's disease. The 17 cases in this series have been extensively studied histologically to establish a distinction between lymphadenoma and granulomatous thymoma. The course of the disease does not give much help as patients with Hodgkin's disease who have been adequately treated may on occasion survive as long as those in our granulomatous category (seven over four years, including two of seven years, one of nine, and one of 13 years). Four patients died from secondary deposits, mostly in the lungs, but in none of our cases was the spleen or liver involved and glandular involvement in the neck, axilla, and groins with one exception did not occur. These patients had all had irradiation which in recent cases included the neck but not the axillae nor groins.

The lymphoid and teratomatous thymomas have been small in number and not sufficient to deserve comment apart from their sinister malignancy. The two teratomas were included because of the complete mixture of all elements (thymic and teratomatous) within the excised tumour. The one tumour that was originally classified as lymphoid has been commented on in the text.

Generally speaking our experience suggests that an active policy must be directed towards the treatment of any intrathoracic mass suspected of being a thymic tumour. Excision gives the best results if this can be completed, but considerable regression is obtained as the result of irradiation in cases where surgery is impracticable or incomplete. It may also serve as a valuable preliminary to surgery but should not be used solely as an alternative.

Recent years have seen a more extensive use of thymectomy in patients with myasthenia gravis This, we feel, is justified even if a tumour cannot 
be demonstrated. The hazards of the operation have been greatly reduced by the introduction of respiratory control technique, and some benefit is nearly always obtained. When an unexpected tumour is present the long-term results suggest that surgery offers great benefits to most patients in respect of the myasthenic process in addition to the obvious advantages of having a tumour removed.

Our interest in this subject has extended over a number of years and we are indebted to our friends and colleagues, who have been generous with their help and loan of material. Members of the staffs of the Middlesex, Harefield, and London Chest Hospitals and the National Hospital, Queen Square, have contributed to this study, and to them we are most grateful. We should like to mention by name Messrs. J. W. Jackson, C. W. James, and K. Ross for permission to use patients on whom they had operated.

The technical and photographic staff of various hospitals have been instrumental in providing the illustrations, which are but a fraction of the total study.

\section{REFERENCES}

Castleman, B., Iverson, L., and Menendez, V. P. (1956). Localized mediastinal lymph-node hyperplasia resembling thymoma. Cancer, 9, 822.

- (1960). Pathology of the thymus gland in myasthenia gravis. In Thymectomy for Myasthenia Gravis, by H. R. Viets and R. S. Schwab, pp. 51-66. Thomas, Springfield, Illinois.

Iverson, L. (1956). Thymoma: a review and reclassification. Amer. J.으 Path., 32, 695.

Keynes, G. L. (1946). The surgery of the thymus gland. Brit. J. Surg., 33, 201. (1954). Surgery of the thymus gland; second (and third) ${ }^{\circ}$ thoughts. Lancet, 1, 1197.

Lambert, E. H., and Rooke, E. D. (1965). Myasthenic state and lung $\vec{\omega}$ cancer. In The Remote Effects of Cancer on the Nervous System (Contemporary Neurology Symposia, Vol. 1), ed. Lord Brain and $F$ F. H. Norris, pp. 67-80. Grune and Stratton, New York. Lattes, $R$. (1962). Thymoma and other tumors of the thymus: anj
analysis of 107 cases. Cancer, 15, 1224.

Lowenhaupt, E. (1948). Tumors of the thymus in relation to the $\omega$ thymic epithelial anlage. Ibid., 1, 547.

- and Brown, R. (1951). Carcinoma of the thymus of granulo- $\vec{c}$ matous type. A clinical and pathological study. Ibid., 4, 1193.

Perlo, V. P., Schwab, R. S., and Castleman, B. (1965). Myasthenia음 gravis and thymoma. In The Remote Effects of Cancer on the Nervous System (Contemporary Neurology Symposia, Vol. 1), ed. Lord Brain and F. H. Norris, pp. 55-66. Grune and Stratton,
New York.

Rowland, L. P., Hoefer, P. F. A., and Aranow, H. (1960). Myasthenic syndromes. Res. Publ. Ass. nerv. ment. Dis., 38, 548.

Sellors, T. H. (1961). Surgery of the thymus gland. Bull. Soc. int. O Chir., 20, 315.

Thomson, A. D., and Thackray, A. C. (1957). The histology of tumours of the thymus. Brit. J. Cancer, 11, 346.

Weigert, C. (1901). Pathologisch-anatomischer Beitrag zur Erb'schen Krankheit (Myasthenia gravis). Neurol. Zbl., 20, 597. 